ARTICLE

https://doi.org/10.1038/s41467-018-07789-4

\title{
A viral-fusion-peptide-like molecular switch drives membrane insertion of botulinum neurotoxin A1
}

\author{
Kwok-ho Lam', Zhuojun Guo ${ }^{2}$, Nadja Krez ${ }^{3}$, Tsutomu Matsui ${ }^{4}$, Kay Perry ${ }^{5}$, Jasmin Weisemann ${ }^{3}$,
} Andreas Rummel (1) ${ }^{3}$, Mark E. Bowen ${ }^{2} \&$ Rongsheng Jin (1) ${ }^{1}$

Botulinum neurotoxin (BoNT) delivers its protease domain across the vesicle membrane to enter the neuronal cytosol upon vesicle acidification. This process is mediated by its translocation domain $\left(\mathrm{H}_{\mathrm{N}}\right)$, but the molecular mechanism underlying membrane insertion of $\mathrm{H}_{\mathrm{N}}$ remains poorly understood. Here, we report two crystal structures of BoNT/A1 $\mathrm{H}_{N}$ that reveal a novel molecular switch (termed BoNT-switch) in $\mathrm{H}_{N}$, where buried $\alpha$-helices transform into surface-exposed hydrophobic $\beta$-hairpins triggered by acidic $\mathrm{pH}$. Locking the BoNT-switch by disulfide trapping inhibited the association of $\mathrm{H}_{N}$ with anionic liposomes, blocked channel formation by $\mathrm{H}_{N}$, and reduced the neurotoxicity of BoNT/A1 by up to 180fold. Single particle counting studies showed that an acidic environment tends to promote BoNT/A1 self-association on liposomes, which is partly regulated by the BoNT-switch. These findings suggest that the BoNT-switch flips out upon exposure to the acidic endosomal $\mathrm{pH}$, which enables membrane insertion of $\mathrm{H}_{N}$ that subsequently leads to LC delivery.

\footnotetext{
${ }^{1}$ Department of Physiology and Biophysics, University of California, Irvine 92697 CA, USA. ${ }^{2}$ Department of Physiology and Biophysics, Stony Brook University, Stony Brook 11794 NY, USA. ${ }^{3}$ Institut für Toxikologie, Medizinische Hochschule Hannover, Hannover 30623, Germany. ${ }^{4}$ Stanford Synchrotron Radiation Lightsource, SLAC National Accelerator Laboratory, Stanford University, Menlo Park 94025 CA, USA. ${ }^{5}$ NE-CAT and Department of Chemistry and Chemical Biology, Argonne National Laboratory, Cornell University, Argonne 60439 IL, USA. Correspondence and requests for materials should be addressed to R.J. (email: r.jin@uci.edu)
} 
M any bacterial toxins and viruses gain access to intracellular targets in their hosts by exploiting the endocytic pathway, such as anthrax toxin ${ }^{1}$, diphtheria toxin ${ }^{2}$, Ebola virus ${ }^{3}$, and vesicular stomatitis virus ${ }^{4}$. Some of the toxins and viruses detect acidification of the vesicle lumen and subsequently change from a water-soluble form to a membraneembedded form to exert their functions. Botulinum neurotoxins (BoNTs), the most poisonous biological toxins for mammals, are speculated to exploit a similar mechanism to block neurotransmitter release at neuromuscular junctions that results in fatal botulism ${ }^{5}$. As some BoNTs, in particular type A1 (BoNT/A1), are powerful medicines as well as potential bio-weapons ${ }^{6,7}$, a better understanding of the molecular mechanism underlying BoNT/A1 membrane translocation has great potential for improving its therapeutic efficacy and developing antitoxins.

There are seven established BoNT serotypes, designated as BoNT/A to $G$, which include more than 40 subtypes $^{8}$. BoNTs are members of single-chain $A B$ toxins that also include diphtheria toxin and tetanus neurotoxin ${ }^{9}$. A BoNT molecule consists of a light chain (LC) and a heavy chain (HC) that are linked by a disulfide bridge ${ }^{10-12}$. LC is a zinc-dependent endopeptidase that is delivered into the cytosol where it degrades SNARE proteins to inhibit synaptic vesicle exocytosis. Membrane translocation of LC is mediated by $\mathrm{HC}$, which can be subdivided into a translocation domain $\left(\mathrm{H}_{\mathrm{N}}\right)$ and a receptorbinding domain $\left(\mathrm{H}_{\mathrm{C}}\right)$ (Fig. 1a). The N-terminus of $\mathrm{H}_{\mathrm{N}}$ forms an extended "belt" that wraps around the LC and links $\mathrm{H}_{\mathrm{N}}$ to LC via a disulfide bond ${ }^{13}$. The BoNT $\mathrm{H}_{\mathrm{C}}$ binds a specific protein receptor and a ganglioside on the neuronal surface to enable toxin endocytosis ${ }^{14-19}$

The mechanisms underlying BoNT membrane insertion and LC translocation have been the subject of considerable debates. Earlier studies showed that BoNT/A1 translocated LC in planar lipid bilayer in the presence of a transmembrane $\mathrm{pH}$ gradient, an electrochemical potential, and a redox gradient ${ }^{20,21}$. It was proposed that acidic $\mathrm{pH}$ might induce a structural change of BoNT and promote its interaction with phospholipids ${ }^{17}$, which is similar to other pore forming toxins ${ }^{2,22,23}$. Although no conformational change was detected in BoNT at acidic pH in the available crystal structures ${ }^{24}$, it underwent an unknown structural rearrangement after binding to ganglioside-containing membranes ${ }^{25-29}$. Furthermore, the $\mathrm{H}_{\mathrm{N}}$ core lacking the "belt" (termed $\mathrm{tH}_{\mathrm{N}}$ thereafter, Fig. 1a) was shown to form an ion channel independent of $\mathrm{pH}$, and no clear structural change was detected by spectroscopic methods at acidic $\mathrm{pH}^{30-32}$. Other regions of $\mathrm{H}_{\mathrm{N}}$ have also been proposed to be involved in membrane insertion ${ }^{33,34}$. However, the structural rearrangement of BoNT during LC delivery, particularly the trigger for membrane insertion of $\mathrm{H}_{\mathrm{N}}$, has not been visualized.

To better understand the mechanism of BoNT membrane translocation, we determined the crystal structure of $\mathrm{tH}_{\mathrm{N}}$ of BoNT/A1 $\left(\mathrm{tH}_{\mathrm{N}} \mathrm{A}\right.$, residues $\left.\mathrm{K} 547-\mathrm{K} 871\right)$ at $\mathrm{pH}$ 5.1, as well as a point mutation of $\mathrm{tH}_{\mathrm{N}} \mathrm{A}\left(\mathrm{tH}_{\mathrm{N}} \mathrm{A}^{\mathrm{F} 658 \mathrm{E}}\right)$ at $\mathrm{pH}$ 8.5. To our surprise, these two structures revealed a previously unrecognized amphipathic region of $\mathrm{H}_{\mathrm{N}}$ (residues E620-F667, termed the BoNT-switch) that undergoes a profound $\mathrm{pH}$-dependent structural rearrangement to form surface-exposed $\beta$-hairpins. Furthermore, the BoNT-switch shares a high sequence similarity with the internal fusion loop (IFL) of Ebola virus glycoprotein 2. A combination of structural studies, biochemical assays, singlemolecule subunit counting, and functional assays confirmed that, upon endosome acidification, the BoNT-switch triggers the transformation of BoNT/A1 into a transmembrane state for LC delivery, which is essential for its extreme toxicity.

\section{Results}

Acidic $\mathbf{p H}$ triggers membrane insertion of $\mathbf{t H}_{\mathrm{N}} \mathbf{A}$. The $\mathrm{H}_{\mathrm{N}}$ of BoNTs has evaded structural studies due to problematic protein folding during recombinant expression ${ }^{31,32}$. We and others found that $\mathrm{H}_{\mathrm{N}} \mathrm{A}$ primarily formed inclusion bodies in Escherichia coli, which could be refolded when stabilized by detergent. However, we found that the beltless $\mathrm{H}_{\mathrm{N}}$ (termed $\mathrm{tH}_{\mathrm{N}} \mathrm{A}$ ) could be successfully expressed in soluble form and purified to high homogeneity (Supplementary Fig. 1a). Size-exclusion chromatography-coupled small-angle X-ray scattering (SEC-SAXS) showed that $\mathrm{tH}_{\mathrm{N}} \mathrm{A}$ was monomeric at neutral $\mathrm{pH}$ and displayed a conformation comparable to that observed in the crystal structure of full-length BoNT/A1 ${ }^{10}$ (Supplementary Fig. 1b, c). Thus, deletion of the belt region improves protein folding of $\mathrm{H}_{\mathrm{N}}$ without altering its tertiary structure.

Some earlier studies suggested that low $\mathrm{pH}$ and anionic phospholipids may promote the membrane interaction of $\mathrm{H}_{\mathrm{N}}{ }^{30-32,35}$. We conducted a liposome co-sedimentation assay to investigate the effect of $\mathrm{pH}$ and lipid composition on $\mathrm{tH}_{\mathrm{N}} \mathrm{A}-$-membrane association. We found that $\mathrm{tH}_{\mathrm{N}} \mathrm{A}$ was copelleted with asolectin liposomes at $\mathrm{pH} 4.4$ or 5.0, but not at $\mathrm{pH} 7.5$, indicating that acidic $\mathrm{pH}$ enhances the association of $\mathrm{tH}_{\mathrm{N}} \mathrm{A}$ with lipid (Fig. 1b). We then examined liposomes containing different ratios of anionic phosphatidylserine (PS) and neutral phosphatidylcholine (PC) lipids and found that $\mathrm{tH}_{\mathrm{N}} \mathrm{A}$ binding to liposomes at $\mathrm{pH} 4.4$ was greatly enhanced by increasing concentrations of PS. This demonstrates that $\mathrm{tH}_{\mathrm{N}} \mathrm{A}$ shows selectivity for anionic lipids (Fig. 1c).

We further characterized the membrane insertion of $\mathrm{tH}_{\mathrm{N}} \mathrm{A}$ using two complementary assays. First, we monitored the ability of $\mathrm{tH}_{\mathrm{N}} \mathrm{A}$ to permeabilize calcein-entrapped liposomes. We found that $\mathrm{tH}_{\mathrm{N}} \mathrm{A}$ increased the rate of calcein release at acidic $\mathrm{pH}$ when liposomes contained the anionic phospholipid 1,2-dioleoyl-sn-glycero-3-phospho-L-serine (DOPS) or asolectin, but not when liposomes contained only the neutral lipid 1,2-dioleoyl-sn-glycero-3-phosphocholine (DOPC) (Fig. 1d). We then studied the ability of $\mathrm{tH}_{\mathrm{N}} \mathrm{A}$ to dissipate valinomycininduced membrane potential in liposomes containing 20\% DOPS at different $\mathrm{pH}$ (Fig. 1e) ${ }^{36,37}$, and found that $\mathrm{tH}_{\mathrm{N}} \mathrm{A}$ induced membrane depolarization at acidic $\mathrm{pH}(<5.0)$. It is worth noting that this $\mathrm{pH}$ value is close to the estimated luminal surface $\mathrm{pH}$ of synaptic vesicles, which could be one unit lower than that inside the lumen $(\sim 5.5)^{38,39}$. These results consistently demonstrate that $\mathrm{tH}_{\mathrm{N}} \mathrm{A}$ favorably interacts and inserts into membranes containing anionic lipids at acidic $\mathrm{pH}$.

Acidic pH triggers a structural rearrangement of $\mathrm{tH}_{\mathrm{N}} \mathrm{A}$. To better understand how acidic $\mathrm{pH}$ triggers membrane insertion of $\mathrm{tH}_{\mathrm{N}} \mathrm{A}$, we crystallized $\mathrm{tH}_{\mathrm{N}} \mathrm{A}$ at $\mathrm{pH} 5.1$ and determined the structure at $2.7 \AA$ resolution (Methods) (Table 1). Two molecules of $\mathrm{tH}_{\mathrm{N}} \mathrm{A}$ form a homodimer in the asymmetric unit (Fig. 2a). Each $\mathrm{tH}_{\mathrm{N}} \mathrm{A}$ is composed of two long coiled-coil helices that are wrapped around by several shorter helices at the two ends, and the overall structure of $t \mathrm{H}_{\mathrm{N}} \mathrm{A}$ is similar to that observed in fulllength BoNT/A1 crystallized at a neutral $\mathrm{pH}^{10}$. However, we observed a major conformational change in a central helical bundle (residues E620-F667) of $\mathrm{H}_{\mathrm{N}}$. This region, which we term the "BoNT-switch", is composed of disordered loops and three short helices $\left(\alpha_{A}-\alpha_{C}\right)$ at neutral $\mathrm{pH}$, but changes into five $\beta$ strands $(\beta 1-\beta 5)$ at acidic $\mathrm{pH}$ (Fig. 2b).

At neutral $\mathrm{pH}, \alpha_{\mathrm{A}}$ helix and the surrounding loops (residues I630-Y648, named $\beta 2 / \beta 3$ loop thereafter, labeled green in Fig. $2 b$ ) are partially buried in a hydrophobic groove located between $\alpha_{B}$ (residues F652-S659) and the coiled-coil helices (Fig. 2b). The 




b

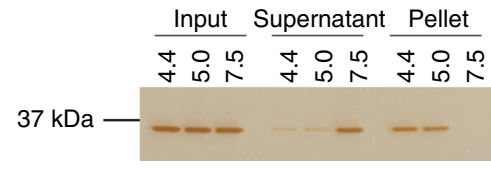

d

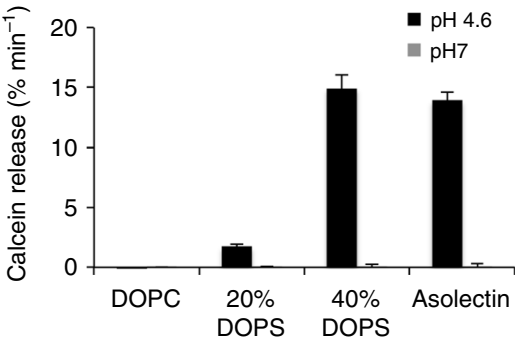

C

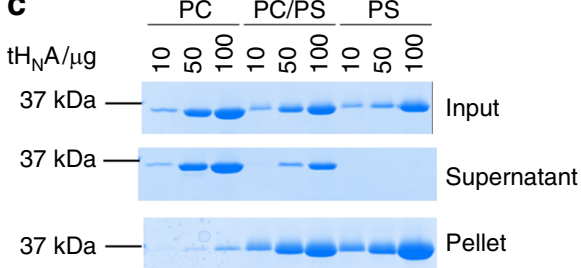

e



Fig. 1 Biochemical characterization of $\mathrm{tH}_{N} A$. a The structure of BoNT/A1 (PDB code 3BTA). LC, the "belt", $t H_{N}$, and $H_{C}$ are colored green, marine, orange, and cyan, respectively. The disulfide linkage between $L C$ and $H_{N}$ is shown as salmon sphere and the BoNT-switch is highlighted in magenta. $\mathbf{b}$, c Cosedimentation of $\mathrm{tH}_{\mathrm{N}} \mathrm{A}$ with liposomes. $\mathrm{tH}_{\mathrm{N}} \mathrm{A}$ was incubated with asolectin liposomes at $\mathrm{pH} 7.5,5.0$ or 4.4 (b); or incubated with liposomes containing $60 / 40$ mol\% PC/cholesterol, 30/30/40 mol\% PC/PS/cholesterol, or 60/40 mol\% PS/cholesterol at pH 4.4 (c). After liposomes were pelleted, the proteins in input, supernatant, and pellet fractions were analyzed by SDS-PAGE. These experiments were performed in triplicate and quantification of protein band intensities are shown in Supplementary Fig. 11. Uncropped images of gels are shown in Supplementary Fig. 13. d Calcein dye release assay. $\mathrm{HH}_{\mathrm{N}} \mathrm{A}$ was tested with four different liposomes loaded with $50 \mathrm{mM}$ calcein at pH 4.6 or pH 7.0, whereas liposomes were composed of DOPC alone, $80 / 20 \mathrm{~mol} \%$ DOPC/DOPS, 60/40 mol\% DOPC/DOPS, or asolectin. The rate of calcein dye release was determined based on the increase of fluorescence at $525 \mathrm{~nm}$ during excitation at $493 \mathrm{~nm}$. Error bars indicate SD of triplicate measurements. e Membrane depolarization assay. Liposomes composed of 70/20/10 mol\% DOPC/DOPS/cholesterol were polarized at a positive internal voltage by adding valinomycin in the presence of a transmembrane $\mathrm{KCl}$ gradient. Membrane potential was measured using the voltage-sensitive fluorescence dye ANS. After 3 min, t $\mathrm{H}_{\mathrm{N}} \mathrm{A}$ was added at the indicated buffer $\mathrm{pH}$. The data are presented as mean \pm S.D., $n=3$

conformation of this region is similar among BoNT/B, D, E, and TeNT. These contacts are stabilized by Y636 that interacts with F585, M732, and I784 (Fig. 2b). At acidic $\mathrm{pH}$, the $\alpha_{\mathrm{A}}$ protrudes outward to form the center of the $\beta 2 / \beta 3$ hairpin. This leaves the hydrophobic groove exposed to solvent, thus helices $\alpha_{\mathrm{B}}$ and $\alpha_{C}$ transform into the $\beta 4 / \beta 5$ hairpin to partly shield the solventexposed surface. The low $\mathrm{pH}$ conformation is facilitated by several non-polar residues (V653, F658, and F667). These residues are solvent-exposed at neutral $\mathrm{pH}$, but flip inward at acidic $\mathrm{pH}$. Notably, the highly conserved Y636 that is important for stabilizing the local structure at neutral $\mathrm{pH}$ flips out to be solvent exposed at acidic $\mathrm{pH}$. Interestingly, the original position of Y636 is taken over by F658. This finding suggests that F658 may contribute to the $\mathrm{pH}$-dependent conformational transition. Additionally, the BoNT-switch contains several glycine residues (G638, G644, G654, and G660) that likely provide the conformational flexibility to accommodate such a dramatic structural transition (Fig. 2b). Interestingly, the Propka algorithm ${ }^{40}$ predicted that three acidic residues (E620, D629, and E666) located within the BoNT-switch have increased pKa values in the context of the neutral $\mathrm{pH}$ conformation ${ }^{38}$. Two of these residues, D629 and E666, are locked in hydrogen bonds to S794 and Y250, respectively, while these interactions are released at acidic pH (Supplementary Fig. 2). Therefore, we suspect that these titratable charged residues could be involved in sensing low $\mathrm{pH}$.

As this is the only crystal structure for the isolated $\mathrm{tH}_{\mathrm{N}} \mathrm{A}$ and all the other available structures are for the full-length BoNT/A or $\mathrm{LC} / \mathrm{A}-\mathrm{H}_{\mathrm{N}} \mathrm{A}^{10,41}$, it would be informative for structural analysis if we could obtain the structure of $\mathrm{tH}_{\mathrm{N}} \mathrm{A}$, without the influence of other BoNT/A domains, at a neutral $\mathrm{pH}$. Interestingly, diffraction-quality crystals of $\mathrm{tH}_{\mathrm{N}} \mathrm{A}$ could only be obtained at an acidic $\mathrm{pH}$ despite thorough crystallization screens at various $\mathrm{pH}$. We suspected that the isolated $\mathrm{tH}_{\mathrm{N}} \mathrm{A}$ domain may be prone 


\begin{tabular}{|c|c|c|}
\hline & $\mathbf{t H}_{\mathrm{N}} \mathrm{A}$ & $\mathrm{tH}_{\mathrm{N}} \mathrm{A}^{\mathrm{F} 658 \mathrm{E}}$ \\
\hline \multicolumn{3}{|l|}{ Data collection } \\
\hline Space group & H 32 & P 6322 \\
\hline \multicolumn{3}{|l|}{ Cell dimensions } \\
\hline$a, b, c(\AA)$ & $\begin{array}{l}167.66,167.66 \\
222.83\end{array}$ & $\begin{array}{l}158.27,158.27 \\
123.97\end{array}$ \\
\hline$\alpha, \beta, \gamma\left(^{\circ}\right)$ & $90,90,120$ & $90,90,120$ \\
\hline Resolution $(\AA)$ & $\begin{array}{l}52.01-2.70 \\
(2.83-2.70)^{\mathrm{a}}\end{array}$ & $\begin{array}{l}42.87-3.02 \\
(3.20-3.02)\end{array}$ \\
\hline$R_{\text {merge }}$ & $0.064(0.609)$ & $0.093(0.616)$ \\
\hline $\mathrm{CC} 1 / 2$ & $0.999(0.711)$ & $0.999(0.886)$ \\
\hline $\mathrm{I} / \sigma(\mathrm{I})$ & $12.8(2.0)$ & $15(3.6)$ \\
\hline Completeness (\%) & $99.3(99.1)$ & $99.9(100)$ \\
\hline Redundancy & $4.6(4.1)$ & $9.1(9.3)$ \\
\hline \multicolumn{3}{|l|}{ Refinement } \\
\hline Resolution $(\AA)$ & $52.01-2.70$ & $42.87-3.02$ \\
\hline No. reflections & 32906 & 18514 \\
\hline Reflections used for & 1662 & 946 \\
\hline \multicolumn{3}{|l|}{$R_{\text {free }}$} \\
\hline $\mathrm{R}_{\text {work }} / \mathrm{R}_{\text {free }}$ & $0.209 / 0.223$ & $0.182 / 0.237$ \\
\hline No. atoms & 5176 & 2647 \\
\hline Protein & 5144 & 2602 \\
\hline Ligand/ion & 5 & 45 \\
\hline Water & 27 & - \\
\hline B-factors & 85.70 & 83.40 \\
\hline Protein & 85.80 & 83.00 \\
\hline Ligand/ion & 117.60 & 107.10 \\
\hline Water & 65.50 & - \\
\hline \multicolumn{3}{|l|}{ R.m.s. deviations } \\
\hline Bond lengths $(\AA)$ & 0.009 & 0.010 \\
\hline Bond angles $\left({ }^{\circ}\right)$ & 1.167 & 1.116 \\
\hline
\end{tabular}

One crystal was used for each structure

aStatistics for the highest resolution shell are shown in parentheses

to adopting the acidic $\mathrm{pH}$ conformation needed for $\mathrm{LC}$ translocation, and its neutral $\mathrm{pH}$ conformation could be stabilized by $\mathrm{LC} / \mathrm{A}$ and/or $\mathrm{H}_{\mathrm{C}} \mathrm{A}$. Taking advantage of our new crystal structure, we set out to look for point mutations on $\mathrm{tH}_{\mathrm{N}} \mathrm{A}$ that shift the structural equilibrium of $\mathrm{tH}_{\mathrm{N}} \mathrm{A}$ more towards the neutral $\mathrm{pH}$ conformation as opposed to the acidic $\mathrm{pH}$ conformation. After extensive search and screening, we found that $\mathrm{tH}_{\mathrm{N}} \mathrm{A}$ carrying a single point mutation of F658E could be crystallized at pH 8.5 and we determined its structure at $3.02 \AA$ (Table 1 and Supplementary Fig. 3a). This result is consistent with our structural analysis that suggested F658E may destabilize the acidic $\mathrm{pH}$ conformation, but does not directly affect the neutral $\mathrm{pH}$ conformation (Fig. 2b). We found that the structure of $\mathrm{tH}_{\mathrm{N}} \mathrm{A}^{\mathrm{F} 658 \mathrm{E}}$ is highly similar to the corresponding region in fulllength BoNT/A that was crystallized at a neutral $\mathrm{pH}$ (root-meansquare deviation of $\sim 0.96 \AA$ ). Notably, the BoNT-switch adopts an almost identical structure in $\mathrm{tH}_{\mathrm{N}} \mathrm{A}^{\mathrm{F} 658 \mathrm{E}}$ and the full-length toxin (Supplementary Fig. 3b). Taken together, the structures of $\mathrm{tH}_{\mathrm{N}} \mathrm{A}$ at $\mathrm{pH} 5.1$ and $\mathrm{tH}_{\mathrm{N}} \mathrm{A}^{\mathrm{F} 658 \mathrm{E}}$ at $\mathrm{pH} 8.5$ allow us to directly visualize how the environmental $\mathrm{pH}$ regulates the conformation of the BoNT-switch.

The BoNT-switch is similar to the Ebola GP2 fusion loop. The structural rearrangement of the BoNT-switch causes a $\sim 21 \%$ increase in the solvent-accessible hydrophobic surface in $\mathrm{tH}_{\mathrm{N}} \mathrm{A}^{42}$, which is largely ascribed to the formation of the $\beta 2 / \beta 3$ loop (Fig. $2 b, c)$. The structural and sequence analyses of the BoNTswitch indicate that the solvent-exposed $\beta 2 / \beta 3$ loop is favorable for interacting with lipids, as supported by the hydropathy analysis of the BoNT/A sequence ${ }^{43,44}$ (Supplementary Fig. 4). Interestingly, these hydrophobic patches in $\beta 2 / \beta 3$, which are energetically not favored in an aqueous environment, are shielded by forming a homodimer in the crystal lattice, which buries a surface area of $\sim 2,625 \AA^{2}$ per molecule (PDBePISA). Specifically, the $\mathrm{tH}_{\mathrm{N}} \mathrm{A}$ homodimer forms a two-side flattened $\beta$-barrel that is stabilized by swapping the $\beta 2 / \beta 3$ hairpin between the two protomers, which forms an antiparallel $\beta$ sheet with $\beta 1, \beta 4$, and $\beta 5$ (Fig. 2a). Dimer formation is stabilized by hydrogen bonds primarily involving the main-chain atoms of $\beta 2$ and $\beta 5$ (Supplementary Fig. 5a). As a result, most of the exposed hydrophobic side-chains of the $\beta$-hairpins are buried within the $\mathrm{tH}_{\mathrm{N}} \mathrm{A}$ homodimer in the crystal structure (Supplementary Fig. 5b, c).

Remarkably, we found that the $\beta 2 / \beta 3$ loop contains a stretch of hydrophobic residues rich in aliphatic side-chains, which shares a high sequence similarity to a lipid-binding peptide of the glycoprotein 2 (GP2) IFL of Ebola virus, a member of the Filoviridae family of enveloped viruses. IFL is known to control viral-host membrane fusion at low endosomal $\mathrm{pH}$ by directly engaging the host membrane ${ }^{45}$ (Fig. 2b). The loops in both BoNT/A1 and GP2 contain an "aromatic-hydrophobic-glycine" tripeptide motif flanked by two proline residues, which would favorably interact with the interfacial region of lipid bilayers ${ }^{46}$. Amino acid sequence alignments among the 44 known BoNT subtypes, including the recently identified BoNT/HA ${ }^{47}$, BoNT/ $\mathrm{X}^{48}$, and eBoNT/J (aka BoNT/En) ${ }^{49,50}$, as well as TeNT, showed that the sequence of the $\beta 2 / \beta 3$ loop is highly conserved, suggesting a functional role for this loop in BoNTs (Fig. 2c). We noted that the second proline (P639) is conserved among BoNT/A, C, D, G, X, and TeNT, but this residue is replaced by a leucine in BoNT/B, E, F, and $\mathrm{HA}$ or an asparagine in eBoNT/J (Supplementary Fig. 6). Such variation may indicate that the structure of the BoNT-switch when inserted into membrane could be different from that of the viral-fusion-loop of GP2.

The BoNT-switch is important to the membrane insertion of $\mathbf{H}_{\mathbf{N}}$. To further characterize the role of the BoNT-switch in membrane insertion of $\mathrm{tH}_{\mathrm{N}} \mathrm{A}$, we engineered a covalent tethering between loop $\mathrm{A}_{\mathrm{A}}$ and $\alpha_{\mathrm{B}}$ by replacing $\mathrm{S} 622$ and V653 with cysteines (named $\mathrm{tH}_{\mathrm{N}} \mathrm{A}^{\mathrm{DS}}$ ) (Fig. $2 \mathrm{~b}$ and Supplementary Fig. 7). The crystal structures showed that these two solvent-exposed residues are $5.3 \AA$ apart (C $\beta-C \beta$ distance) when BoNT/A1 is at a neutral $\mathrm{pH}$, but they move away from each other (15.5 $\AA$ ) upon the conformational change induced by acidic $\mathrm{pH}$. Therefore, the disulfide bridge between S622C and V653C will inhibit the helixto-strand transition of $\alpha_{B}$ when oxidized, and the inhibition will be released when reduced. To monitor exposure of hydrophobic surface in $\mathrm{tH}_{\mathrm{N}} \mathrm{A}$, we used 8-anilinonaphthalene-1-sulfonic acid (ANS) as an indicator that displays increased fluorescence intensity when it binds to hydrophobic patches in a protein (Fig. 3a). We found that ANS intensity in the presence of $\mathrm{tH}_{\mathrm{N}} \mathrm{A}$ remained unchanged at $\mathrm{pH} 5-7$, but dramatically increased at $\mathrm{pH}$ below 5.0. This is consistent with our structural data showing exposure of hydrophobic surface in $\mathrm{tH}_{\mathrm{N}} \mathrm{A}$ at acidic $\mathrm{pH}$. The transitional $\mathrm{pH}$ for $\mathrm{tH}_{\mathrm{N}} \mathrm{A}(\sim 4.82)$ is similar to that reported previously for full-length BoNT/A $(\sim 4.55)^{29}$. We then asked whether the structural change in $\mathrm{tH}_{\mathrm{N}} \mathrm{A}^{\mathrm{DS}}$ could be regulated by the engineered disulfide bond. The reduced $\mathrm{tH}_{\mathrm{N}} \mathrm{A}^{\mathrm{DS}}$ showed an acidic-pH-dependent increase in ANS fluorescence that was similar to the $\mathrm{WT} \mathrm{tH}_{\mathrm{N}} \mathrm{A}$, indicating that the cysteine mutations on S622 and V653 did not affect the BoNT-switch. In contrast, the oxidized $\mathrm{tH}_{\mathrm{N}} \mathrm{A}^{\mathrm{DS}}$ did not exhibit a $\mathrm{pH}$-dependent change in ANS fluorescence as there was only a subtle intensity increase at acidic $\mathrm{pH}$. Therefore, the engineered disulfide linkage prevented the acid-induced release of the BoNT-switch.

In a parallel approach, we performed a fluorescence-based thermal shift assay to examine how the disulfide bridge affects the 



Fig. 2 Crystal structure of $\mathrm{tH}_{\mathrm{N}} \mathrm{A}$ at an acidic $\mathrm{pH}$. a Structure of a $\mathrm{tH}_{\mathrm{N}} \mathrm{A}$ dimer (orange and green) observed in an asymmetric unit. The BoNT-switch of chain A is colored in magenta. b The structures of the BoNT-switch at neutral (left) and acidic pH (right). The $\beta 2 / \beta 3$ loop is highlighted in green. Residues discussed in the text are shown as sticks, $\mathrm{C} \alpha$ atoms of conserved glycines are drawn in spheres. (Boxed) Sequence alignment of the $\beta 2 / \beta 3$ loop and the internal fusion loops of Ebola virus (EBOV) and Marburg virus (MARV) glycoproteins were generated with ESPript 3.0. c Amino acid sequences of E620F667 (BoNT/A1 numbering) from 42 BoNT subtypes ${ }^{8}$, TeNT, BoNT/X, and eBoNT/J were aligned (Clustal Omega) and depicted as sequence logo. Individual sequences are shown in Supplementary Fig. 6. The secondary structure of the BoNT/A1-switch at neutral and acidic pH is shown on the top. The $\beta 2 / \beta 3$ loop is underlined in green. The solvent-accessible surface area (SASA) of the corresponding residues is shown at the bottom. SASA was calculated using the program POPS ${ }^{42}$. The SASA values are for the entire residue and represent fraction of exposed surface area

structure and stability of $\mathrm{tH}_{\mathrm{N}} \mathrm{A}^{\mathrm{DS}}$ (Supplementary Fig. 8). At neutral $\mathrm{pH}$, the melting temperature $(\mathrm{Tm})$ of the oxidized $\mathrm{tH}_{\mathrm{N}} \mathrm{A}^{\mathrm{DS}}$, but not the reduced $\mathrm{tH}_{\mathrm{N}} \mathrm{A}^{\mathrm{DS}}$, increased by $\sim 15 \%$ relative to $\mathrm{WT} \mathrm{tH}_{\mathrm{N}} \mathrm{A}$, indicating that the engineered disulfide bond stabilized $\mathrm{tH}_{\mathrm{N}} \mathrm{A}$. The Tm could not be measured at $\mathrm{pH} 4.6$ for either WT $\mathrm{tH}_{\mathrm{N}} \mathrm{A}$ or the reduced $\mathrm{tH}_{\mathrm{N}} \mathrm{A}^{\mathrm{DS}}$ due to high fluorescence intensity, because large hydrophobic surfaces in $\mathrm{tH}_{\mathrm{N}} \mathrm{A}$ were exposed at acidic $\mathrm{pH}$. However, the $\mathrm{Tm}$ of the oxidized $\mathrm{tH}_{\mathrm{N}} \mathrm{A}^{\mathrm{DS}}$ could be measured at $\mathrm{pH} 4.6$, which only decreased by $\sim 6 \%$ in comparison to the $\mathrm{Tm}$ at neutral $\mathrm{pH}$, suggesting that the oxidized $\mathrm{tH}_{\mathrm{N}} \mathrm{A}^{\mathrm{DS}}$ is trapped in the neutral-pH-like conformation and insensitive to $\mathrm{pH}$ changes. These findings demonstrate that the BoNT-switch regulates the exposure of hydrophobic surface at acidic $\mathrm{pH}$.
Using $\mathrm{tH}_{\mathrm{N}} \mathrm{A}^{\mathrm{DS}}$ as a unique molecular probe, we further examined lipid association of $\mathrm{tH}_{\mathrm{N}} \mathrm{A}$ using a liposome cosedimentation assay (Fig. $3 \mathrm{~b}$ ). The WT $\mathrm{tH}_{\mathrm{N}} \mathrm{A}$ and the reduced $\mathrm{tH}_{\mathrm{N}} \mathrm{A}^{\mathrm{DS}}$ co-sedimented with anionic liposomes containing $20 \%$ DOPS at $\mathrm{pH} 4.6$ in a lipid concentration-dependent fashion. In contrast, association of the oxidized $\mathrm{tH}_{\mathrm{N}} \mathrm{A}^{\mathrm{DS}}$ with liposomes was significantly reduced at all lipid concentrations tested. Furthermore, the oxidized $\mathrm{tH}_{\mathrm{N}} \mathrm{A}^{\mathrm{DS}}$ exhibited a marked decrease in both the rate of calcein dye release and the ability to dissipate the membrane potential of a polarized membrane in liposomes, while the reduced $\mathrm{tH}_{\mathrm{N}} \mathrm{A}^{\mathrm{DS}}$ behaved like the WT $\mathrm{tH}_{\mathrm{N}} \mathrm{A}$ (Fig. $3 \mathrm{c}$, d). These findings prove that the acidic $\mathrm{pH}$ induced structural change of the BoNT-switch is necessary for $\mathrm{tH}_{\mathrm{N}} \mathrm{A}$ to transform from a water-soluble state to a transmembrane state. 


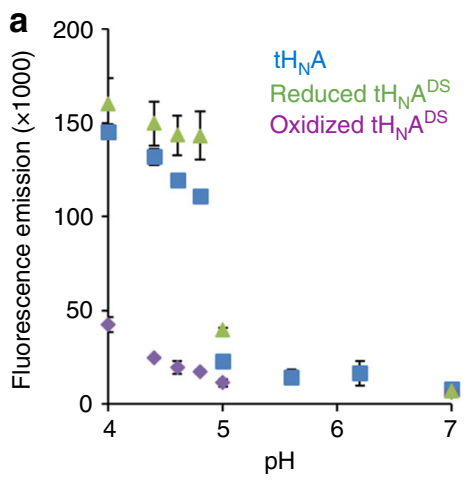

C



b

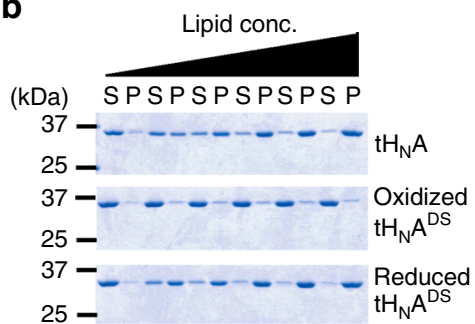

d

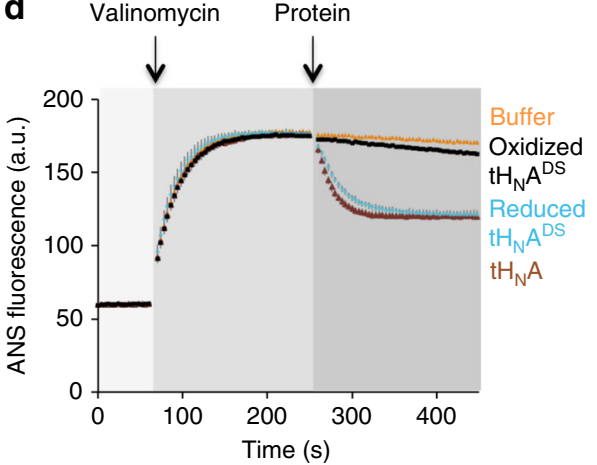

Fig. 3 Modulating the conformation of the BoNT-switch using an engineered disulfide bond trapping. $\mathrm{tH}_{N} \mathrm{~A}^{\mathrm{DS}}$ was analyzed by four independent assays: a ANS binding; b liposome association: liposome co-sedimentation was conducted by incubating the WT $\mathrm{H}_{N} \mathrm{~A}$ or $\mathrm{tH}_{N} \mathrm{~A}^{\mathrm{DS}}$ with different concentrations of liposomes containing 20\% DOPS and 80\% OBPC. Supernatant (S) and pellet (P) fractions were analyzed by SDS-PAGE. Quantification of protein band intensities are shown in Supplementary Fig. 12. Uncropped images of gels are shown in Supplementary Fig. 13; c calcein dye release; and d membrane depolarization assay. $5 \mathrm{mM}$ TCEP was added for the reaction of reduced $\mathrm{HH}_{N} \mathrm{~A}^{\mathrm{DS}}$ and no reducing agent was used for wild type or oxidized $t H_{N} A^{D S}$.

The data are presented as mean \pm S.D., $n=3$

The BoNT-switch regulates self-association of BoNT/A1. Since the $\mathrm{tH}_{\mathrm{N}} \mathrm{A}$ homodimer observed in the crystal lattice could be affected by crystal packing, we used analytical size-exclusion chromatography to examine the effect of $\mathrm{pH}$ on self-association of $\mathrm{tH}_{\mathrm{N}} \mathrm{A}$ in solution. We found that $\mathrm{tH}_{\mathrm{N}} \mathrm{A}$ shifted to a higher oligomeric state at acidic $\mathrm{pH}(<5.4)$ in a concentrationdependent manner (Supplementary Fig. 9a, b). Importantly, the oxidized $\mathrm{tH}_{\mathrm{N}} \mathrm{A}^{\mathrm{DS}}$ remained monomeric at $\mathrm{pH}$ 4.6, while the reduced form shifted to oligomers like the $\mathrm{WT} \mathrm{tH}_{\mathrm{N}} \mathrm{A}$ (Supplementary Fig. 9c). Therefore, $\mathrm{tH}_{\mathrm{N}} \mathrm{A}$ self-association seems to be needed to protect the unique conformation of the BoNT-switch at acidic $\mathrm{pH}$, whereas such protection could be provided by other BoNT domains in the context of the full-length toxin or by the vesicle membrane in vivo. Furthermore, the micromolar $\mathrm{tH}_{\mathrm{N}} \mathrm{A}$ concentration used in this assay is much higher than the physiological concentration of BoNT/A1 at the neuromuscular junctions. Therefore, $\mathrm{tH}_{\mathrm{N}} \mathrm{A}$ dimerization may not be directly relevant for BoNT/A1 function in vivo. In support of this, we found that the full-length BoNT/A1i (a genetically inactivated BoNT/A1 carrying R363A/Y366F mutations) does not exhibit $\mathrm{pH}$-dependent self-association in solution (Supplementary Fig. 9d).

To investigate whether membrane binding may trigger BoNT/ A1 self-association, we used single-molecule photobleaching to count the number of BoNT/A1 molecules recruited to single liposomes containing gangliosides. Photobleach step counting has been widely used to study protein oligomerization on the membrane ${ }^{51-53}$. Since BoNT/A1 contains several functionally important cysteine residues, we could not chemically-label BoNT/ A1. To circumvent this, we fluorescently labeled a BoNT/A1specific camelid heavy-chain-only antibody (ciA-D12) that binds to LC with high affinity $\left(\mathrm{K}_{\mathrm{d}} \sim 0.2 \mathrm{nM}\right)$ and does not affect BoNT/ A1 function ${ }^{54}$. Importantly, the ciA-D12-BoNT/A1i interaction is not affected by acidic pH (Supplementary Fig. 10). An engineered cysteine residue (S142C) in ciA-D12 was labeled to $>99 \%$ efficiency with Alexa Fluor 647 maleimide (termed D12*). The D12*-BoNT/A1i complex was assembled and purified by size-exclusion chromatography.

The BoNT/A1i-D12* complex was reconstituted on $100 \mathrm{~nm}$ anionic liposomes containing $10 \%$ polysialoganglioside GT1b. The liposomes also contained $0.5 \mathrm{~mol} \%$ biotin-labeled lipids to allow liposomes to be attached to a streptavidin-coated microscope slide while unbound proteins were washed away by rinsing. To allow co-localization of protein and liposomes, we included $0.5 \mathrm{~mol} \%$ Rhodamine-labeled lipids and imaged the samples with two-color Total Internal Reflection Fluorescence (TIRF) microscopy. Liposomes were deposited under dilute conditions to achieve optical resolution of individual liposomes, which appeared as diffraction-limited spots (Fig. 4a). Under our incubation conditions ( $10 \mathrm{nM}$ protein with $0.5 \mathrm{mg} / \mathrm{mL}$ lipid), we estimated that $\sim 10 \%$ of liposomes were occupied by protein molecules. The low surface density and low liposome occupancy both help to minimize the probability of false co-localization of proteins.

The number of BoNT/A1i-D12* complexes on a liposome was determined by counting Alexa Fluor 647 photobleaching steps for diffraction-limited spots that also contained Rhodamine emission

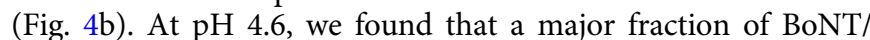
A1i-D12* fluorescent spots displayed single-step bleaching with a smaller fraction showing multi-step bleaching up to five steps (Fig. 4c). We observed $66.2 \pm 1.7 \%, 23.2 \pm 2.4 \%, 8.2 \pm 1.5 \%$, $1.9 \pm 1.2 \%$, and $0.5 \pm 0.5 \%$ for one to five-step events, respectively. 
a

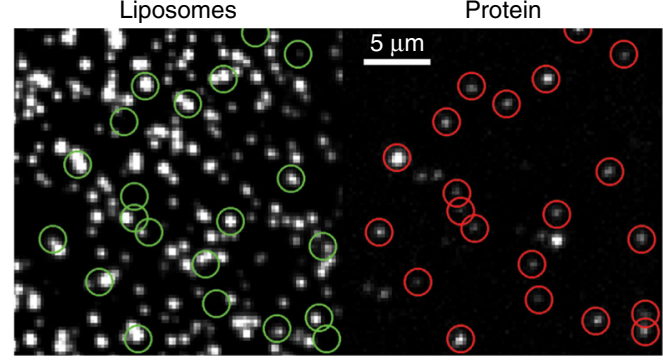

C



d



b
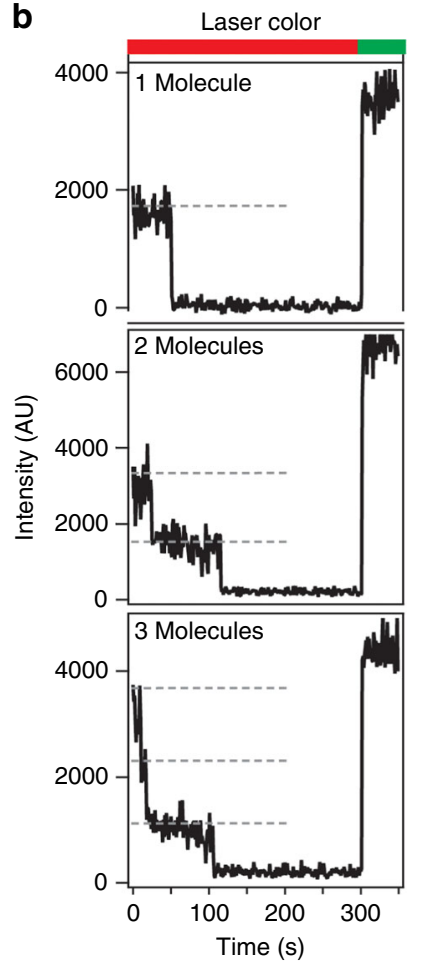

Fig. 4 Single-molecule analysis of the distribution of BoNT/A1i on individual liposomes. a Representative TIRF microscope images showing co-localization of Alexa 647-labeled BoNT/A1i-D12* complexes (right) with rhodamine-labeled liposomes (left). In these experiments, $<10 \%$ of liposomes were occupied by protein to minimize co-localization. The circled spots on the right were used for photobleaching analysis only when co-localized with rhodamine fluorescence. $\mathbf{b}$ Representative time traces of fluorescence emission from spots used to assess the oligomerization state. The bar above the panel indicates the excitation with red laser used to first bleach the Alexa 647 followed by green laser to probe for rhodamine emission. Examples are shown for 1-, 2-, and 3-step photobleaching events. Dashed lines highlight individual bleaching steps. (c) Distribution of bleaching steps for BoNT/A1i-D12* at pH 4.6 ( $n=935)$ and $\mathrm{pH} 7.4(n=482)$. The increase in 1-step events and decrease in 3-step events upon raising the pH to 7.4 were statistically significant (asterisk) with $p=0.0001$ and 0.0065 , respectively. The decrease in 2-step events was just above significance with $p=0.077$. $\mathbf{d}$ Distribution of photobleaching steps for oxidized BoNT/A1iDS-D12* at pH $4.6(n=589)$ and pH $7.4(n=535)$. No significant differences were observed when the BoNT-switch was locked by a disulfide bond. Error bars indicate standard error of measurement (SEM) from replicate analysis

At neutral $\mathrm{pH}$, we found a decrease in protein co-localization events. Specifically, two- and three-step events were reduced and higher order events disappeared entirely while the onestep bleaching events increased by $16.8 \pm 3.8 \%$. This finding suggests that, while BoNT/A1i binds to membranes predominantly as monomer at neutral or acidic $\mathrm{pH}$ on liposomes we tested here, an acidic environment increased the degree of BoNT/A self-association. Interestingly, low-pH-dependent selfassociation of BoNT was previously observed for BoNT/B on artificial membranes ${ }^{27}$.

To test whether locking the BoNT-switch could affect selfassociation of BoNT/A1 on membranes, we incorporated S622C and V653C into the full-length BoNT/A1i (termed BoNT/Ai ${ }^{\mathrm{DS}}$ ). $\mathrm{BoNT} / \mathrm{Ai}^{\mathrm{DS}}$ was oxidized and then assembled with the labeled antibody D $12^{\star}$. We found that the oxidized BoNT/A $1 i^{\mathrm{DS}}$ showed a similar liposome occupancy as the WT toxin, suggesting that locking the BoNT-switch did not significantly affect membrane association of BoNT/A1. We then examined the oligomerization state of BoNT/Ai ${ }^{\mathrm{DS}}$ by analyzing the photobleaching time traces as described above. Notably, locking the BoNT-switch showed significant effect on oligomerization of the full-length toxin (Fig. 4d). The increase in protein oligomerization at $\mathrm{pH} 4.6$ was completely eliminated in the oxidized BoNT/A1i ${ }^{\mathrm{DS}}$, even though BoNT/A1 ${ }^{D S}$ showed the same level of monomers at $\mathrm{pH} 7.4$ as the WT toxin $(82.8 \pm 1.5 \%)$. Taken together, we found that acidic $\mathrm{pH}$ tends to promote BoNT/A1 oligomerization on liposomes, which is partly regulated by the BoNT-switch. The physiological relevance of BoNT/A1 self-association on the vesicle membrane in vivo warrants further investigation.

The BoNT-switch is crucial to the extreme potency of BoNT/ A1. To explore the functional relevance of the BoNT-switch to BoNT toxicity, we incorporated the S622C and V653C mutations 


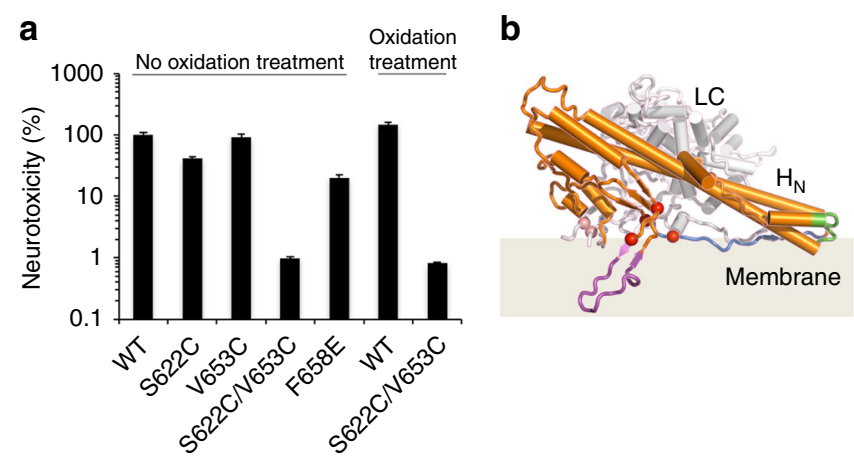

Fig. 5 The BoNT-switch modulates neurotoxicity of BoNT/A1.

a Neurotoxicity of BoNT/A1 variants was analyzed using the MPN assay. The paralytic half-times were determined and converted to the corresponding concentrations of wild-type BoNT/A1 using a concentration-response curve. The resulting toxicities were expressed relative to wild-type BoNT/A1 ( $n=3-6, \pm$ S.D.). b Proposed model for insertion of BoNT/A1 into lipid bilayer. The $\beta 2 / \beta 3$ loop and the two putative membrane-interacting segments, F667-1685 and R827-R836, are colored in magenta, blue, and green, respectively. The inter-chain disulfide bond and four conserved carboxylates (D625, D629, E666, E670) are drawn as salmon and red spheres, respectively

into active BoNT/A1 (termed BoNT/A1 ${ }^{\mathrm{DS}}$ ). Since an endogenous disulfide linkage between LC and $\mathrm{HC}$ is crucial to LC translocation $^{55,56}$, we could not directly measure the toxicity of $\mathrm{BoNT} / \mathrm{A1}{ }^{\mathrm{DS}}$ under reducing conditions. Instead, we generated two single cysteine mutations (BoNT/A1 $1^{\mathrm{S} 622 \mathrm{C}}$ and BoNT/ $\left.\mathrm{A} 1^{\mathrm{V} 653 \mathrm{C}}\right)$ as controls. We then examined the neurotoxicity of BoNT/A1 mutants at motor nerve terminals using ex vivo mouse phrenic nerve hemidiaphragm (MPN) assays ${ }^{57}$ (Fig. 5a). Remarkably, the naturally oxidized BoNT/A1 ${ }^{\mathrm{DS}}$ displayed a $\sim 100$-fold decreased toxicity, while BoNT/A1 V653C and BoNT/ $\mathrm{A} 1^{\mathrm{S} 622 \mathrm{C}}$ behaved like the WT toxin. When BoNT/A1 DS was further oxidized with copper phenanthroline, the decrease in neurotoxicity was $\sim 180$-fold. BoNT/A1 ${ }^{\text {F658E }}$ has a $\sim 5$-fold decreased toxicity, which is likely due to the energetic costs of burying of an acidic residue in a hydrophobic pocket when $t_{N} A$ transits into the acidic-pH conformation during LC translocation (Fig. 2b). These results prove that the structural change in the BoNT-switch as we observed in the crystal structure is essential to the extreme potency of BoNT/A1.

\section{Discussion}

Like many other bacterial toxins and enveloped viruses, the capability of BoNT to trespass the endosomal membrane barrier is crucial for its function 22,58 . To achieve membrane insertion, these proteins commonly carry a buried hydrophobic segment as a molecular switch that is exposed only when the proteins sense the endosomal signals (e.g., acidic $\mathrm{pH}$, enzymatic cleavage, membrane surface charges). Here, we identified such a molecular switch in BoNT/A1 that senses acidic environment and subsequently converts the water-soluble translocation domain into a membrane-competent state. We suggest that the highly conserved $\beta 2 / \beta 3$ loop within the BoNT-switch may be the first part of $\mathrm{H}_{\mathrm{N}}$ to insert into the membrane (Fig. 5b). This model is supported by the observation that two previously proposed membrane-interacting segments of $\mathrm{H}_{\mathrm{N}} \mathrm{A}$ (segments F667-I685 and R827-R836) and the conserved disulfide linkage between LC and $\mathrm{H}_{\mathrm{N}}{ }^{56}$ are close to the $\beta 2 / \beta 3$ loop $33,34,43,44$. Furthermore, conserved carboxylates (D625, D629, E666, and E670) that were suggested to sense acidic $\mathrm{pH}$ and interact with the anionic lipid in their protonated forms ${ }^{59}$ are positioned at the base of the $\beta 2 / \beta 3$ loop, which would favorably interact with a negatively charged membrane at acidic $\mathrm{pH}$.

Our model of membrane binding would require an acidic $\mathrm{pH}$ triggered structural re-orientation of BoNT/A1 to position $\mathrm{H}_{\mathrm{N}} \mathrm{A}$ on the membrane surface. Such a structural rearrangement is possible because the flexible $\mathrm{H}_{\mathrm{N}}-\mathrm{H}_{\mathrm{C}}$ linker allows a $140^{\circ}$ rotation between $\mathrm{H}_{\mathrm{N}}$ and $\mathrm{H}_{\mathrm{C}}$ when BoNT/A1 is bound to the nontoxic nonhemagglutinin (NTNHA) protein at $\mathrm{pH}<6.5$ in the medium progenitor toxin complex (M-PTC) ${ }^{60}$. The driving force for the structural change likely involves acidic $\mathrm{pH}$ and the electrostatic attraction between the electropositive surface of BoNT/A1 with the negatively charged membrane ${ }^{27}$. Interestingly, the $\mathrm{H}_{\mathrm{N}}-\mathrm{H}_{\mathrm{C}}$ linker of TeNT is also modulated by $\mathrm{pH}$, which may play a role in reorienting TeNT for the membrane insertion ${ }^{61}$. Furthermore, we speculate that the belt of BoNT/A1 may modulate the conformational change of $\mathrm{H}_{\mathrm{N}} \mathrm{A}$ by interacting with and shielding the hydrophobic surface of the BoNT-switch. The belt is likely unfolded upon membrane binding and vesicle acidification that may help to release the BoNT-switch.

It is well known that some viral-fusion proteins, such as influenza virus hemagglutinin, vesicular stomatitis virus GP, and Ebola virus GP, contain a hydrophobic loop that is buried at neutral $\mathrm{pH}$, but released at acidic $\mathrm{pH}$ to insert the fusion protein into the lipid bilayer ${ }^{3,46}$. Our complementary structural and functional studies reveal a surprising similarity between the $\beta 2 / \beta 3$ loop of the BoNT-switch, which is conserved in almost all known BoNTs, and the IFL of Ebola virus GP2. Moreover, $\mathrm{H}_{\mathrm{N}} \mathrm{A}$ carries a pair of long $a$-helices that resemble the coiled-coil viral-fusion proteins (e.g., influenza hemagglutinin and HIV-1 gp41) ${ }^{10}$. These viral proteins undergo dramatic structural reorganization of these helices after the fusion loop penetrates the membrane ${ }^{3,62,63}$. We speculate that the formation of protein-conducting channel of BoNT may similarly involve a large reorganization of the long helices within $\mathrm{tH}_{\mathrm{N}} \mathrm{A}$.

Interestingly, the $\beta 2 / \beta 3$ loop of BoNT is situated at the middle of the long helices that likely break down into shorter helical segments following membrane insertion. In this scenario, our model may represent the first step of membrane insertion, in which the $\beta 2 / \beta 3$ loop brings the long helices of $H_{N} A$ closer to the vesicle membrane and promotes its reorganization to form the translocation channel. Another possibility is that the $\beta 2 / \beta 3$ loop may constitute part of the transmembrane hairpin and $\mathrm{H}_{\mathrm{N}} \mathrm{A}$ may form $\beta$-hairpin channels reminiscent of anthrax toxin ${ }^{22}$. Formation of a $\beta$-hairpin channel requires oligomerization of BoNT, which is also consistent with our observation that acidic $\mathrm{pH}$ tends to promote BoNT/A1 oligomerization on liposomes, which is partly regulated by the BoNT-switch. It is worth noting that our data argues that the mechanism of BoNT membrane insertion is different from some other bacterial toxins, such as diphtheria toxin and colicin, which also have an $\alpha$-helical translocation domain similar to BoNT. Those toxins do not have a viral-fusion-peptide-like switch, and they insert into membranes through exposure of a helical hairpin without a significant change in secondary structures 64 .

In summary, our studies demonstrate that BoNT/A1 contains a molecular switch that regulates channel formation and LC delivery, so it only happens in the right cellular location at the right time. The importance of the BoNT-switch to the neurotoxicity of BoNT/A1 suggests that blocking the conformational transition with an antibody or small molecule inhibitors holds promise as an alternative strategy to neutralize these extremely lethal toxins. This is also supported by a report that antibodies from the sera of some cervical dystonia patients with immuneresistance to BoNT/A1 bound to a region of BoNT/A1 (S659-G677) that is within the BoNT-switch ${ }^{65}$. These unique human antibodies are worthy of further characterization. Because 
of its functional importance and high sequence conservation among all known BoNTs, the BoNT-switch could be an ideal target for the development of the long sought-after cross-serotype therapeutic intervention for botulism.

\section{Methods}

Statistical method. No statistical method was used to predetermine sample size. The experiments were not randomized and were not performed with blinding to the conditions of the experiments.

Construct design and cloning. The sequences corresponding to full-length BoNT/ Al carrying two substitutions at the active site (R363A/Y366F) (BoNT/A1i), and $\mathrm{tH}_{\mathrm{N}} \mathrm{A}$ (residues K547-K871) from BoNT/A1-producing C. botulinum strain $62 \mathrm{~A}$ were cloned into expression vectors pGEX-6p-1 and pCDFduet-1, respectively. ciA-D12 was cloned into pGEX-6p-1. Sequences of PCR primers are provided in Supplementary Table 1 . To facilitate protein purification, a $\mathrm{His}_{6}$-tag followed by a PreScission cleavage site was introduced to the $\mathrm{N}$-terminus of $\mathrm{tH}_{\mathrm{N}} \mathrm{A}$. BoNT/A1i and ciA-D12 were produced with an N-terminal GST-tag followed by a PreScission cleavage site. All t $\mathrm{H}_{\mathrm{N}} \mathrm{A}, \mathrm{BoNT} / \mathrm{A} 1, \mathrm{BoNT} / \mathrm{Ali}$, and ciA-D12 mutations were generated by QuikChange site-directed mutagenesis (Agilent).

Protein expression and purification. All recombinant proteins were expressed in the E. coli strain BL21-RIL (DE3) (Novagen). Bacteria expressing BoNT/A1i and ciA-D12 were grown at $37^{\circ} \mathrm{C}$ in $\mathrm{LB}$ medium in the presence of the appropriate selecting antibiotics. Expression was induced with $1 \mathrm{mM}$ isopropyl-b-Dthiogalactopyranoside (IPTG) when $\mathrm{OD}_{600}$ reached 0.6 . The temperature was then decreased to $16^{\circ} \mathrm{C}$ and expression was continued for $16 \mathrm{~h}$. For the expression of $\mathrm{tH}_{\mathrm{N}} \mathrm{A}$, bacteria were grown at $37^{\circ} \mathrm{C}$ in $\mathrm{TB}$ medium and expression was induced with $1 \mathrm{mM}$ IPTG when $\mathrm{OD}_{600}$ reached 0.9 . The temperature was then decreased to $19^{\circ} \mathrm{C}$ and expression was continued for $16 \mathrm{~h}$. The cells were harvested by centrifugation and stored at $-20^{\circ} \mathrm{C}$ until use.

For protein purification, bacteria were resuspended in Tris buffer $(50 \mathrm{mM}$ Tris $\mathrm{pH}$ 8.0, $400 \mathrm{mM} \mathrm{NaCl}$ ) with $0.4 \mathrm{mM}$ PMSF and lysed by sonication. His ${ }_{6}$-tagged proteins $\left(\mathrm{tH}_{\mathrm{N}} \mathrm{A}\right.$ wild type and mutants) were purified using a Ni-NTA (nitrilotriacetic acid, Qiagen) affinity column in a buffer containing $50 \mathrm{mM}$ Tris (pH 8.0), $400 \mathrm{mM} \mathrm{NaCl}$, and $10 \mathrm{mM}$ imidazole and subsequently eluted in the same buffer containing $150 \mathrm{mM}$ imidazole. The eluted fractions of each protein were pooled and dialyzed overnight at $4{ }^{\circ} \mathrm{C}$ against a buffer composed of $20 \mathrm{mM}$ Hepes ( $\mathrm{pH} 8.0)$ and $50 \mathrm{mM} \mathrm{NaCl}$, followed by His-tag removal using PreScission protease. The protein was further purified by MonoQ ion-exchange chromatography (GE Healthcare) in a buffer containing $20 \mathrm{mM}$ Hepes ( $\mathrm{pH} 8.0$ ) and eluted with a $\mathrm{NaCl}$ gradient, followed by Superdex-75 size-exclusion chromatography (SEC; GE Healthcare, Germany) in $10 \mathrm{mM}$ Hepes (pH 7.0) and $150 \mathrm{mM} \mathrm{NaCl}$. GST-tagged BoNT/A1i and the ciA-D12 were purified using Glutathione Sepharose 4B resins (GE Healthcare) in $50 \mathrm{mM}$ Tris (pH 8.0), $400 \mathrm{mM}$ $\mathrm{NaCl}$, and eluted from the resins after on-column cleavage using PreScission protease. The protein was further purified by Superdex-200 Increase or Superdex75 SEC in $10 \mathrm{mM}$ Hepes (pH 7.0) and $150 \mathrm{mM} \mathrm{NaCl}$ for BoNT/Ali and ciA-D12, respectively. Each protein was concentrated to $\sim 5 \mathrm{mg} / \mathrm{ml}$ using Amicon Ultra centrifugal filters (Millipore) and stored at $-80^{\circ} \mathrm{C}$ until used for further characterization or crystallization.

Wild type and mutated recombinant full-length activated BoNT/A1 were produced under biosafety level 2 containment (project number GAA A/Z 40654/3/ 123) recombinantly in K12 E. coli strain in Dr. Rummel's lab ${ }^{66}$. BoNT/A1 variants carrying $\mathrm{C}$-terminal $\mathrm{His}_{6}$-tag were purified on $\mathrm{Co}^{2+}$-Talon matrix (Takara Bio Europe S.A.S., France) and eluted with $50 \mathrm{mM}$ Tris- $\mathrm{HCl}(\mathrm{pH} 8.0), 150 \mathrm{mM} \mathrm{NaCl}$, and $250 \mathrm{mM}$ imidazole. For proteolytic activation, BoNT/A1 was incubated for $16 \mathrm{~h}$ at room temperature with $0.01 \mathrm{U}$ bovine thrombin (Sigma-Aldrich Chemie $\mathrm{GmbH}$, Germany) per $\mu \mathrm{g}$ of BoNT/A1. Subsequent gel filtration (Superdex-200 SEC; GE Healthcare, Germany) was performed in phosphate buffered saline ( $\mathrm{pH}$ 7.4).

The purified $\mathrm{tH}_{\mathrm{N}} \mathrm{A}^{\mathrm{DS}}$ and BoNT/A1 ${ }^{\mathrm{DS}}$ were oxidized by copper 1,10 phenanthroline in vitro. Oxidation of the $\mathrm{tH}_{\mathrm{N}} \mathrm{A}^{\mathrm{DS}}$ mutant was confirmed by gelshift analysis (Supplementary Fig. 7b).

The purified ciA-D12 (S124C) was labeled with Alexa Fluor $\mathrm{C}_{2} 647$ maleimide (Molecular Probes) according to the manufacturer's instructions. The labeled ciA-D12 was further purified by MonoQ ion-exchange chromatography in $10 \mathrm{mM}$ Hepes ( $\mathrm{pH} \mathrm{8.0)}$ and eluted with a $\mathrm{NaCl}$ gradient. The calculated dye to protein ratio was $\sim 1$ mole of dye per mole of ciA-D12. BoNT/A1i-ciA-D12 complex were prepared by mixing BoNT/A1i and ciA-D12 in 1:1.5 molar ratio and the complex was purified by size-exclusion chromatography using Superdex-200.

Crystallization. Initial crystallization screens were performed using a Phoenix crystallization robot (Art Robbins Instruments) and high-throughput crystallization screen kits (Hampton Research), followed by extensive manual optimization. The best single crystals of $\mathrm{tH}_{\mathrm{N}} \mathrm{A}$ were grown at $18^{\circ} \mathrm{C}$ by the sitting-drop vapor diffusion method. The protein at a concentration of $5 \mathrm{mg} / \mathrm{ml}$ was mixed in a 2:1 $(\mathrm{v} / \mathrm{v})$ ratio with a reservoir solution containing $1.4 \mathrm{M}$ sodium potassium phosphate
(pH 5.1) and 0.1 M potassium sodium tartrate tetrahydrate. Crystals of $\mathrm{tH}_{\mathrm{N}} \mathrm{A}^{\mathrm{F}}$.58E were grown with a protein concentration at $3 \mathrm{mg} / \mathrm{ml}$ at $18^{\circ} \mathrm{C}$ with a reservoir solution containing $2.4 \mathrm{M}$ ammonium phosphate, $0.1 \mathrm{M}$ Tris (pH 8.5), and $0.05 \%$ $\mathrm{n}$-dodecyl $\beta$-D-maltoside. The crystals of $\mathrm{tH}_{\mathrm{N}} \mathrm{A}$ were cryoprotected in the original mother liquor supplemented with $30 \%(\mathrm{v} / \mathrm{v})$ ethylene glycol. The crystals were dehydrated by air dry for 5 minutes and then frozen in liquid nitrogen. The crystals of $\mathrm{tH}_{\mathrm{N}} \mathrm{A}^{\mathrm{F} 658 \mathrm{E}}$ were cryoprotected with $2.5 \mathrm{M}$ lithium sulfate.

Data collection and structure determination: After screening numerous crystals at the Stanford Synchrotron Radiation Lightsource (SSRL) or Advanced Photon Source (APS), the best X-ray diffraction datasets for $\mathrm{tH}_{\mathrm{N}} \mathrm{A}$ and $\mathrm{tH}_{\mathrm{N}} \mathrm{A}^{\mathrm{F}}{ }^{658 \mathrm{E}}$ crystals were collected at $100 \mathrm{~K}$ at beam line BL9-2, SSRL. The data were processed with iMOSFLM $^{67}$. Data collection statistics are summarized in Table 1. The structure of $\mathrm{tH}_{\mathrm{N}} \mathrm{A}$ or $\mathrm{tH}_{\mathrm{N}} \mathrm{A}^{\mathrm{F} 658 \mathrm{E}}$ was determined by molecular replacement using the Phaser software ${ }^{68}$ with $\mathrm{tH}_{\mathrm{N}} \mathrm{A}$ of BoNT/A1 as the search model (PDB code $\left.3 \mathrm{VOA}\right)^{60}$. Manual model building and refinement was performed in COOT $^{69}$, PHENIX $^{70}$, and CCP 4 suite $^{71}$ in an iterative manner. The refinement progress was monitored with the free $\mathrm{R}$ value using a $5 \%$ randomly selected test $\operatorname{set}^{72}$. The structures were validated through the MolProbity ${ }^{73}$ and showed excellent stereochemistry. Structural refinement statistics are listed in Table 1. Residues 858-871 of chain A and residue 871 of chain $\mathrm{B}$ of $\mathrm{tH}_{\mathrm{N}} \mathrm{A}$ and residues $647-649$ of $\mathrm{tH}_{\mathrm{N}} \mathrm{A}^{\mathrm{F} 658 \mathrm{E}}$ are invisible in the electron density map that likely indicates local flexibility. One and nine phosphate molecules were identified in the crystal structures of $\mathrm{tH}_{\mathrm{N}} \mathrm{A}$ and $\mathrm{tH}_{\mathrm{N}} \mathrm{A}^{\mathrm{F} 658 \mathrm{E}}$, respectively, that could be attributed to the high phosphate concentration in the corresponding crystallization buffer. All structure figures were prepared with PyMol (http://www.pymol.org).

8-anilinonaphthalene-1-sulfonic acid binding assay. The wild type or mutant $\mathrm{tH}_{\mathrm{N}} \mathrm{A}$ was incubated at $0.1 \mathrm{mg} / \mathrm{ml}(\sim 2.68 \mu \mathrm{M})$ with $100 \mu \mathrm{M}$ ANS for ten minutes in either $50 \mathrm{mM}$ sodium acetate ( $\mathrm{pH} 4.0-5.6), 50 \mathrm{mM}$ sodium cacodylate ( $\mathrm{pH} 6.2$ ), or $50 \mathrm{mM}$ Hepes (pH 7.0). All buffers contained $100 \mathrm{mM} \mathrm{NaCl}$. Fluorescence spectra were recorded at $25^{\circ} \mathrm{C}$ in a Molecular Devices SpectraMax M2e spectrophotometer with excitation at $370 \mathrm{~nm}$. The emission spectrum was collected from 420 to $640 \mathrm{~nm}$. The fluorescence intensity was corrected by subtraction of background fluorescence from ANS in buffer lacking protein. Fluorescence emission was calculated as the area under the spectra. Error bars indicate SD of three replicate measurements.

Thermal denaturation assay. The thermal stability of wild type or mutant $t \mathrm{H}_{\mathrm{N}} \mathrm{A}$ was measured using a fluorescence-based thermal shift assay on a StepOne real-time PCR machine (Life Technologies). Immediately before the experiment, the protein $(2.7 \mu \mathrm{M})$ was mixed with the fluorescent dye SYPRO Orange (Sigma-Aldrich) at pH 7.0 or pH 4.6. The samples were heated from $25^{\circ} \mathrm{C}$ to $90^{\circ} \mathrm{C}$ in $\sim 45 \mathrm{~min}$. The midpoint of the protein-melting curve (Tm) was determined using the analysis software provided by the instrument manufacturer. The data obtained from three independent experiments were averaged to generate the bar graph. The Tm of $\mathrm{tH}_{\mathrm{N}} \mathrm{A}$ wild type and reduced $\mathrm{tH}_{\mathrm{N}} \mathrm{A}^{\mathrm{DS}}$ at $\mathrm{pH} 4.6$ is not determined due to high fluorescence signal at starting temperature.

Analytical size-exclusion chromatography. $\mathrm{tH}_{\mathrm{N}} \mathrm{A}$ at protein concentrations ranging from 0.1 to $1 \mathrm{mg} / \mathrm{ml}(\sim 2.7-27 \mu \mathrm{M})$ were incubated at $4{ }^{\circ} \mathrm{C}$ for 30 minutes in various buffers that contained $0.1 \mathrm{M} \mathrm{NaCl}$ and either $50 \mathrm{mM}$ sodium acetate $(\mathrm{pH}$ 4.4-5.6) or $50 \mathrm{mM}$ Hepes (pH 7.4). BoNT/Ali at $4 \mathrm{mg} / \mathrm{ml}(27 \mu \mathrm{M})$ was incubated in buffers at $\mathrm{pH} 4.4$ or $\mathrm{pH}$ 7.4. Reduced $\mathrm{tH}_{\mathrm{N}} \mathrm{A}^{\mathrm{DS}}$ was prepared by pre-incubation with $5 \mathrm{mM}$ TCEP. Protein oligomerization was resolved using Superdex-200 SEC.

Liposome co-sedimentation assays. Liposomes were prepared by extrusion method using Avanti Mini Extruder according to manufacturer's protocol. Briefly, lipids (Avanti Polar Lipid) were dissolved in chloroform while GT1b trisodium salt (Santa Cruz Biotechnology) was dissolved in methanol. The lipids at the indicated molar ratios were mixed and then dried under nitrogen gas and placed under vacuum for at least $2 \mathrm{~h}$. The dried lipids were rehydrated and were subjected to five rounds of freezing and thawing cycles. Unilamellar vesicles were prepared by extrusion through a $100 \mathrm{~nm}$ pore membrane using an Avanti Mini Extruder according to the manufacturer's instructions.

To study the $\mathrm{pH}$-dependence of $\mathrm{tH}_{\mathrm{N}} \mathrm{A}$-lipid association, $0.2 \mu \mathrm{M}$ protein was incubated with $0.15 \mathrm{mg} / \mathrm{ml}$ asolectin liposomes (Sigma-Aldrich) in $150 \mathrm{mM} \mathrm{NaCl}$ with either $20 \mathrm{mM}$ sodium acetate ( $\mathrm{pH} 4.4-5.0$ ) or $20 \mathrm{mM}$ Hepes ( $\mathrm{pH} 7.5$ ) at room temperature for $2 \mathrm{~h}$. The samples were centrifuged at $160,000 \times \mathrm{g}$ for $40 \mathrm{~min}$. The supernatant was removed and the pellets were resuspended twice in the same buffer and were re-centrifuged. Liposome-bound proteins were analyzed by comparing the supernatant and pellet fractions on SDS-PAGE.

Effect of lipid composition on $\mathrm{tH}_{\mathrm{N}} \mathrm{A}$-lipid binding was studied by mixing $0.27-2.7 \mu \mathrm{M}$ of $\mathrm{tH}_{\mathrm{N}} \mathrm{A}$ with $0.1 \mathrm{mg} / \mathrm{ml}$ liposome containing either $60 \% \mathrm{~L}-\alpha-$ phosphatidylcholine (PC), $40 \%$ cholesterol; $60 \%$ L- $\alpha$-phosphatidylserine (PS), $40 \%$ cholesterol; or $30 \%$ PC, 30\% PS, 40\% cholesterol (Encapsular Nano Sciences). The protein-liposome mixture was incubated in $0.1 \mathrm{M} \mathrm{NaCl}, 50 \mathrm{mM}$ sodium acetate $(\mathrm{pH} 4.4)$ at room temperature for $2 \mathrm{~h}$ and centrifuged.

The effect of disulfide formation in the BoNT-switch on $\mathrm{tH}_{\mathrm{N}} \mathrm{A}$-lipid binding was studied by a low-centrifugal field protocol as described using vesicles 
containing 1-oleoyl-2-(9,10-dibromostearoyl)phosphatidylcholine (OBPC $)^{74}$. OBPC has density of $1.2 \mathrm{~g} / \mathrm{cm}^{3}$ and sediments easily in relatively low centrifugal field ${ }^{75}$. A volume of $0.2 \mu \mathrm{M} \mathrm{tH} \mathrm{H}_{\mathrm{N}} \mathrm{A}$ or mutants were incubated with liposomes composed of $80 \%$ OBPC and $20 \%$ DOPS in $0.1 \mathrm{M} \mathrm{NaCl}, 50 \mathrm{mM}$ sodium acetate ( $\mathrm{pH} 4.6), 1 \mathrm{mM} \mathrm{KCl}$, and $1 \mathrm{mM}$ EDTA at room temperature for $2 \mathrm{~h}$. The samples were spun progressively at $4000 \times, 9000 \times$, and $16,000 \times g$ for 30 min each. Supernatant and pellet were separated and analyzed by SDS-PAGE.

Calcein dye release assay. Dried lipid $(20 \mathrm{mg} / \mathrm{ml})$ was resuspended in $150 \mathrm{mM}$ $\mathrm{NaCl}, 20 \mathrm{mM}$ Hepes (pH 7.0), $1 \mathrm{mM}$ EDTA, $50 \mathrm{mM}$ calcein. Free calcein dye was separated from calcein-entrapped liposomes by desalting (Zeba). Fluorescence was measured on a Spectramax M2e cuvette module with excitation at $493 \mathrm{~nm}$ and emission at $525 \mathrm{~nm}$. In the assay, liposomes were diluted either in $150 \mathrm{mM} \mathrm{NaCl}$, $20 \mathrm{mM}$ sodium acetate (pH 4.6), $1 \mathrm{mM}$ EDTA, or in $150 \mathrm{mM} \mathrm{NaCl}, 20 \mathrm{mM}$ Hepes $(\mathrm{pH} 7.0), 1 \mathrm{mM}$ EDTA to give a final concentration of $0.2 \mathrm{mM}$ and incubated until the fluorescence signal was stable. Wild type or mutant $t_{\mathrm{N}} \mathrm{A}$ was added at $0.2 \mu \mathrm{M}$ and the fluorescence intensity was recorded for 10 minutes. The reaction was stopped by adding $0.1 \%$ Trion X100. The percentage of fluorescence change was calculated as the $\left(\left(\mathrm{F}-\mathrm{F}_{\text {initial }}\right) / \mathrm{F}_{\text {final }}\right)$.

Membrane depolarization assay. Depolarization was measured as previously described with some modifications ${ }^{36}$. Briefly, liposomes composed of $70 \%$ DOPC, $20 \%$ DOPS, $10 \%$ cholesterol were prepared in $200 \mathrm{mM} \mathrm{NaCl}, 1 \mathrm{mM} \mathrm{KCl}, 10 \mathrm{mM}$ Hepes ( $\mathrm{pH} 7.0)$. To create a trans-positive membrane potential $(+135 \mathrm{mV})$, liposomes were diluted in $200 \mathrm{mM} \mathrm{KCl}, 1 \mathrm{mM} \mathrm{NaCl}$ with either $10 \mathrm{mM}$ sodium acetate ( $\mathrm{pH} 4.6-5.8)$ or $10 \mathrm{mM}$ Hepes ( $\mathrm{pH} 7.0$ ). Membrane potential was monitored using $6 \mu \mathrm{M}$ ANS. ANS is sensitive to membrane potential and has been used as a measure of the magnitude of the diffusion potential ${ }^{37}$. ANS is strongly fluorescent when bound to lipids and gives an additional increase in fluorescence intensity when a trans-positive potential is present. Valinomycin was added at time 0 -second to give a final concentration of $30 \mathrm{nM}$. At 180-second, wild type, or mutant $\mathrm{tH}_{\mathrm{N}} \mathrm{A}$ were added at $0.2 \mu \mathrm{M}$ and the fluorescence intensity at $490 \mathrm{~nm}$ was monitored for 3 minutes with excitation at $380 \mathrm{~nm}$. The experiments were repeated three times independently.

Mouse phrenic nerve hemidiaphragm assay. The MPN assay was performed employing 20-30 g NMRI mice (Janvier SA, France) as described previously ${ }^{19,57}$. According to $₫ 4$ Abs. 3 (killing of animals for scientific purposes, German animal protection law (TSchG)), animals were sacrificed by trained personnel before dissection of organs and its number reported yearly to the animal welfare officer of the Central Animal Laboratory and to the local authority, Veterinäramt Hannover. First, mice were euthanized by $\mathrm{CO}_{2}$ anesthesia and subsequent exsanguination via an incision of the ventral aspect of the throat. The chest of the cadaver was opened, the phrenic nerve hemidiaphragm tissue was explanted and placed into an organ bath. The phrenic nerve was continuously stimulated at $5-25 \mathrm{~mA}$ with a frequency of $1 \mathrm{~Hz}$ and with a $0.1 \mathrm{~ms}$ pulse duration. Isometric contractions were transformed using a force transducer and recorded with VitroDat Online software (FMI GmbH, Germany). The time required to decrease the amplitude to $50 \%$ of the starting value (paralytic half-time) was determined. To allow comparison of the altered neurotoxicity of mutants with BoNT/A1 wild type, a power function (y(BoNTA1; $0.75,1.5,3.0,6.0 \mathrm{pM})=98.536 \times-0.267, R^{2}=0.9693$ ) was fitted to a

concentration-response curve consisting of four concentrations determined in 3-5 technical replicates. Resulting paralytic half-times of the BoNTA1 mutants were converted to concentrations of the wild type employing the above power functions and finally expressed as relative neurotoxicity.

Single-molecule analysis of oligomerization. ciA-D12 construct was kindly provided by Dr. Charles B. Shoemaker ${ }^{54}$. ciA-D12 contains two buried cysteines that are inaccessible for labeling. An additional cysteine (S124C) was introduced into ciA-D12 through site-directed mutagenesis. Purified ciA-D12 was labeled with Alexa-647 maleimide (Thermo Fisher Scientific) and subsequently purified with cation exchange. The labeling efficiency was determined to be over $99 \%$ using UVVis spectroscopy. BoNT/Ali was expressed and purified as described above. The complexes with D12* were prepared by incubating with a 1.5 -fold excess of D12* Free D12* was removed by Superdex-200 SEC.

Liposomes containing 10\% GT1b, 69\% DOPC, 20\% DOPS, 0.5\% rhodamine$\mathrm{PE}$, and $0.5 \%$ biotin-PE were prepared by extrusion through a $100 \mathrm{~nm}$ pore membrane. To form proteoliposomes, $10 \mathrm{nM}$ BoNT/A1i-D12* or oxidized BoNT/ $\mathrm{Ali}^{\mathrm{DS}}{ }_{-\mathrm{D} 12^{*}}$ was incubated with $0.5 \mathrm{mg} / \mathrm{ml}$ lipid at room temperature for $1 \mathrm{~h}$ at the $\mathrm{pH}$ indicated. The mixture was then diluted 1000 -fold and incubated for 5 minutes in a passivated, quartz microscope chamber functionalized with streptavidin. The biotinylated liposomes were retained and unbound proteins are washed away by exhaustive rinsing with buffer. At the low densities needed for optical resolution of individual liposomes, we could observe sufficient liposomes for statistical analysis, while minimizing the probability that a diffraction-limited spot would contain multiple liposomes. Samples were imaged using a prism-based Total Internal Reflection Fluorescence (TIRF) microscope. Samples were first excited with a laser diode at $640 \mathrm{~nm}$ (Newport Corporation, Irvine, CA) to photobleach Alexa 647labeled BoNT/A1i-D12* or BoNT/A1i ${ }^{\mathrm{DS}}-\mathrm{D} 12^{*}$ molecules followed by excitation with a diode pumped solid state laser at $532 \mathrm{~nm}$ (Newport Corporation, Irvine, CA) to probe for Rhodamine-labeled liposomes. Emission from protein and lipids was separated using an Optosplit ratiometric image splitter (Cairn Research Ltd., Faversham UK) containing a $645 \mathrm{~nm}$ dichroic mirror, a 585/70 band pass filter for Rhodamine, and a 670/30 band pass filter for Alexa 647 (all Chroma, Bellows Falls, VT). The replicate images were relayed to a single iXon EMCCD camera (Andor Technologies, Belfast, UK) at a frame rate of $10 \mathrm{~Hz}$. Data were processed in MATLAB to cross-correlate the replicate images and extract time traces for diffraction-limited spots with intensity above baseline. Single-molecule traces were hand selected based on the exhibition of single-step decays to baseline during 640 illumination and the appearance of Rhodamine emission during 532 illumination.

SAXS data collection and analysis. Purified $t \mathrm{H}_{\mathrm{N}} \mathrm{A}$ was exchanged into a buffer containing $200 \mathrm{mM} \mathrm{NaCl}, 5 \mathrm{mM}$ DTT, $0.1 \mathrm{mM}$ EDTA, $55 \mathrm{mM}$ Hepes (pH 7.0), and the protein samples were concentrated to $10 \mathrm{mg} / \mathrm{ml}$. SEC-SAXS experiment was performed using Bio-SAXS beam line BL4-2 at Stanford Synchrotron Radiation Lightsource (SSRL) in a similar manner to our previous report ${ }^{76}$. Experimental setup and structural parameters are summarized in Supplementary Table 2. Briefly, the program SasTool (http://ssrl.slac.stanford.edu/ saxs/analysis/sastool.htm) was employed for data reduction to generate background-subtracted scattering profiles. The script fplcplots, implemented in the program AUTORG ${ }^{77}$, was used for consecutive Guinier analysis and assessing data quality. Sample was eluted as a sharp peak and no significant radiation damage or concentration dependence was observed during the elution. The theoretical scattering curve from an atomic structure $\left(\mathrm{tH}_{\mathrm{N}} \mathrm{A}\right.$ of $\mathrm{PDB}$ code $3 \mathrm{BTA}$ ) was computed and was fitted with experimental data using the program $\mathrm{CRYSOL}^{78}$. Ab initio modeling was performed using the program DAMMIF ${ }^{79}$ and the averaged and filtered model from 20 independent $a b$ initio models was generated by the program DAMAVER ${ }^{80}$.

\section{Data availability}

Atomic coordinates and structure factors for $\mathrm{tH}_{\mathrm{N}} \mathrm{A}$ and $\mathrm{tH}_{\mathrm{N}} \mathrm{A}^{\mathrm{F} 658 \mathrm{E}}$ have been deposited in the Protein Data Bank under accession codes 6DKK [https://doi.org/ 10.2210/pdb6DKK/pdb] and 6 MHJ [https://doi.org/10.2210/pdb6MHJ/pdb], respectively. All relevant data are available within the paper and its Supplementary Information files.

Received: 7 June 2018 Accepted: 22 November 2018

Published online: 18 December 2018

\section{References}

1. Young, J. A. T. \& Collier, R. J. Anthrax toxin: receptor binding, internalization, pore formation, and translocation. Annu. Rev. Biochem. 76, 243-265 (2007).

2. Ladokhin, A. pH-triggered conformational switching along the membrane insertion pathway of the diphtheria toxin T-domain. Toxins (Basel) $\mathbf{5}$, 1362-1380 (2013).

3. Harrison, S. C. Viral membrane fusion. Virology 479-480, 498-507 (2015).

4. Gruenberg, J. \& Van Der Goot, F. G. Mechanisms of pathogen entry through the endosomal compartments. Nat. Rev. Mol. Cell Biol. 7, 495-504 (2006).

5. Rossetto, O., Pirazzini, M. \& Montecucco, C. Botulinum neurotoxins: genetic structural and mechanistic insights. Nat. Rev. Microbiol. 12, 535-549 (2014).

6. Bigalke, H. Botulinum toxin: application, safety, and limitations. Curr. Top. Microbiol. Immunol. 364, 307-317 (2013).

7. Bigalke, H. \& Rummel, A. Medical aspects of toxin weapons. Toxicology 214, 210-220 (2005).

8. Peck, M. W. et al. Historical perspectives and guidelines for botulinum neurotoxin subtype nomenclature. Toxins $\mathbf{9}, 38$ (2017).

9. Nestorovich, E. M. \& Bezrukov, S. M. Obstructing toxin pathways by targeted pore blockage. Chem. Rev. 112, 6388-6430 (2012).

10. Lacy, D. B., Tepp, W., Cohen, A. C., DasGupta, B. R. \& Stevens, R. C. Crystal structure of botulinum neurotoxin type A and implications for toxicity. Nat. Struct. Biol. 5, 898-902 (1998).

11. Swaminathan, S. \& Eswaramoorthy, S. Structural analysis of the catalytic and binding sites of Clostridium botulinum neurotoxin B. Nat. Struct. Biol. 7, 693-699 (2000).

12. Zanetti, G. et al. Inhibition of botulinum neurotoxins interchain disulfide bond reduction prevents the peripheral neuroparalysis of botulism. Biochem. Pharmacol. 98, 522-530 (2015).

13. Brunger, A. T. et al. Botulinum neurotoxin heavy chain belt as an intramolecular chaperone for the light chain. PLoS Pathog. 3, 1191-1194 (2007).

14. Yao, G. et al. N-linked glycosylation of SV2 is required for binding and uptake of botulinum neurotoxin A. Nat. Struct. Mol. Biol. 23, 656-662 (2016).

15. Lam, K.-H., Yao, G. \& Jin, R. Diverse binding modes, same goal: the receptor recognition mechanism of botulinum neurotoxin. Prog. Biophys. Mol. Biol. $117,225-231$ (2015). 
16. Jin, R., Rummel, A., Binz, T. \& Brunger, A. T. Botulinum neurotoxin B recognizes its protein receptor with high affinity and specificity. Nature 444, 1092-1095 (2006).

17. Montecucco, C. \& Schiavo, G. Structure and function of tetanus and botulinum neurotoxins. Q. Rev. Biophys. 28, 423-472 (1995).

18. Rummel, A. Two Feet on the Membrane: Uptake of Clostridial Neurotoxins. Curr. Top. Microbiol. Immunol. 406, 1-37 (2017)

19. Strotmeier, J. et al. Identification of the synaptic vesicle glycoprotein 2 receptor binding site in botulinum neurotoxin A. FEBS Lett. 588, 1087-1093 (2014).

20. Montal, M. Translocation of botulinum neurotoxin light chain protease by the heavy chain protein-conducting channel. Toxicon 54, 565-569 (2009).

21. Fischer, A. \& Montal, M. Molecular dissection of botulinum neurotoxin reveals interdomain chaperone function. Toxicon 75, 101-107 (2013).

22. Jiang, J., Pentelute, B. L., Collier, R. J. \& Hong Zhou, Z. Atomic structure of anthrax protective antigen pore elucidates toxin translocation. Nature 521, 545-549 (2015).

23. Peraro, M. D. \& Van Der Goot, F. G. Pore-forming toxins: ancient, but never really out of fashion. Nat. Rev. Microbiol. 14, 77-92 (2016).

24. Eswaramoorthy, S., Kumaran, D., Keller, J. \& Swaminathan, S. Role of metals in the biological activity of clostridium botulinum neurotoxins. Biochemistry 43, 2209-2216 (2004).

25. Schiavo, G., Boquet, P., DasGupta, B. R. \& Montecucco, C. Membrane interactions of tetanus and botulinum neurotoxins: a photolabelling study with photoactivatable phospholipids. J. Physiol. Paris 84, 180-187 (1990).

26. Montecucco, C. et al. Interaction of botulinum and tetanus toxins with the lipid bilayer surface. Biochem. J. 251, 379-383 (1988).

27. Sun, S. et al. Receptor binding enables botulinum neurotoxin B to sense low $\mathrm{pH}$ for translocation channel assembly. Cell Host. Microbe 10, 237-247 (2011).

28. Montecucco, C., Schiavo, G. \& Dasgupta, B. R. Effect of pH on the interaction of botulinum neurotoxins A, B and E with liposomes. Biochem. J. 259, 47-53 (1989).

29. Puhar, A., Johnson, E. A., Rossetto, O. \& Montecucco, C. Comparison of the $\mathrm{pH}$-induced conformational change of different clostridial neurotoxins. Biochem. Biophys. Res. Commun. 319, 66-71 (2004).

30. Araye, A. et al. The translocation domain of botulinum neurotoxin A moderates the propensity of the catalytic domain to interact with membranes at acidic pH. PLoS ONE 11, e0153401 (2016).

31. Fischer, A., Sambashivan, S., Brunger, A. T. \& Montal, M. Beltless translocation domain of botulinum neurotoxin A embodies a minimum ionconductive channel. J. Biol. Chem. 287, 1657-1661 (2012).

32. Galloux, M. et al. Membrane interaction of botulinum neurotoxin A translocation (T) domain: the belt region is a regulatory loop for membrane interaction. J. Biol. Chem. 283, 27668-27676 (2008).

33. Mushrush, D. J. et al. Studies of the mechanistic details of the $\mathrm{pH}$-dependent association of botulinum neurotoxin with membranes. J. Biol. Chem. 286, 27011-27018 (2011).

34. Oblatt-Montal, M., Yamazaki, M., Nelson, R. \& Montal, M. Formation of ion channels in lipid bilayers by a peptide with the predicted transmembrane sequence of botulinum neurotoxin A. Protein Sci. 4, 1490-1497 (1995).

35. Fischer, A., Mushrush, D. J., Lacy, D. B. \& Montal, M. Botulinum neurotoxin devoid of receptor binding domain translocates active protease. PLoS Pathog. 4, e1000245 (2008).

36. Menestrina, G., Forti, S. \& Gambale, F. Interaction of tetanus toxin with lipid vesicles. Effects of $\mathrm{pH}$, surface charge, and transmembrane potential on the kinetics of channel formation. Biophys. J. 55, 393-405 (1989).

37. Shiver, J. W. \& Donovan, J. J. Interactions of diphtheria toxin with lipid vesicles: determinants of ion channel formation. Biochim. Et. Biophys. Acta. 903, 48-55 (1987).

38. Pirazzini, M. et al. On the translocation of botulinum and tetanus neurotoxins across the membrane of acidic intracellular compartments. Biochim. Biophys. Acta 1858, 467-474 (2016).

39. Sankaranarayanan, S. \& Ryan, T. A. Real-time measurements of vesicleSNARE recycling in synapses of the central nervous system. Nat. Cell Biol. 2, 197-204 (2000).

40. Bas, D. C., Rogers, D. M. \& Jensen, J. H. Very fast prediction and rationalization of $\mathrm{pKa}$ values for protein-ligand complexes. Proteins Struct. Funct. Genet. 73, 765-783 (2008).

41. Masuyer, G. et al. Crystal structure of a catalytically active, non-toxic endopeptidase derivative of Clostridium botulinum toxin A. Biochem. Biophys. Res. Commun. 381, 50-53 (2009).

42. Cavallo, L., Kleinjung, J. \& Fraternali, F. POPS: A fast algorithm for solvent accessible surface areas at atomic and residue level. Nucleic Acids Res. 31, 3364-3366 (2003).

43. Wimley, W. C. \& White, S. H. Experimentally determined hydrophobicity scale for proteins at membrane interfaces. Nat. Struct. Biol. 3, 842-848 (1996).

44. Lebeda, F. J. \& Olson, M. A. Structural predictions of the channel-forming region of botulinum neurotoxin heavy chain. Toxicon 33, 559-567 (1995).
45. Lee, J. E. \& Saphire, E. O. Ebolavirus glycoprotein structure and mechanism of entry. Future Virol. 4, 621-635 (2009).

46. Gregory, S. M. et al. Structure and function of the complete internal fusion loop from Ebolavirus glycoprotein 2. Proc. Natl Acad. Sci. USA 108, 11211-11216 (2011).

47. Dover, N., Barash, J. R., Hill, K. K., Xie, G. \& Arnon, S. S. Molecular characterization of a novel botulinum neurotoxin type $\mathrm{H}$ gene. J. Infect. Dis. 209, 192-202 (2014).

48. Zhang, S. et al. Identification and characterization of a novel botulinum neurotoxin. Nat. Commun. 8, 14130 (2017).

49. Zhang, $\mathrm{S}$. et al. Identification of a botulinum neurotoxin-like toxin in a commensal strain of enterococcus faecium. Cell Host Microbe 23, 169-176.e6 (2018).

50. Brunt, J., Carter, A. T., Stringer, S. C. \& Peck, M. W. Identification of a novel botulinum neurotoxin gene cluster in Enterococcus. FEBS Lett. 592, 310-317 (2018).

51. Weninger, K., Bowen, M. E., Choi, U. B., Chu, S. \& Brunger, A. T. Accessory proteins stabilize the acceptor complex for synaptobrevin, the 1:1 Syntaxin/ SNAP-25 Complex. Structure 16, 308-320 (2008)

52. Ulbrich, M. H. \& Isacoff, E. Y. Subunit counting in membrane-bound proteins. Nat. Methods 4, 319-321 (2007)

53. Groulx, N., McGuire, H., Laprade, R., Schwartz, J. L. \& Blunck, R. Single molecule fluorescence study of the Bacillus thuringiensis toxin Cry1Aa reveals tetramerization. J. Biol. Chem. 286, 42274-42282 (2011)

54. Mukherjee, J. et al. A novel strategy for development of recombinant antitoxin therapeutics tested in a mouse botulism model. PLoS ONE 7, e29941 (2012).

55. Fischer, A. \& Montal, M. Crucial role of the disulfide bridge between botulinum neurotoxin light and heavy chains in protease translocation across membranes. J. Biol. Chem. 282, 29604-29611 (2007).

56. Pirazzini, M., Rossetto, O., Bolognese, P., Shone, C. C. \& Montecucco, C. Double anchorage to the membrane and intact inter-chain disulfide bond are required for the low $\mathrm{pH}$ induced entry of tetanus and botulinum neurotoxins into neurons. Cell Microbiol. 13, 1731-1743 (2011).

57. Bigalke, H. \& Rummel, A. Botulinum neurotoxins: Qualitative and quantitative analysis using the mouse phrenic nerve hemidiaphragm assay (MPN). Toxins (Basel). 7, 4895-4905 (2015).

58. Leka, O. et al. Diphtheria toxin conformational switching at acidic $\mathrm{pH}$. Febs. J. 281, 2115-2122 (2014).

59. Pirazzini, M. et al. Neutralisation of specific surface carboxylates speeds up translocation of botulinum neurotoxin type B enzymatic domain. FEBS Lett. 587, 3831-3836 (2013).

60. $\mathrm{Gu}, \mathrm{S}$. et al. Botulinum neurotoxin is shielded by NTNHA in an interlocked complex. Science 335, 977-981 (2012).

61. Masuyer, G., Conrad, J. \& Stenmark, P. The structure of the tetanus toxin reveals pH-mediated domain dynamics. EMBO Rep. 18, 1306-1317 (2017).

62. Bullough, P. A., Hughson, F. M., Skehel, J. J. \& Wiley, D. C. Structure of influenza haemagglutinin at the $\mathrm{pH}$ of membrane fusion. Nature 371, 37-43 (1994).

63. Weissenhorn, W., Carfí, A., Lee, K. H., Skehel, J. J. \& Wiley, D. C. Crystal structure of the Ebola virus membrane fusion subunit, GP2, from the envelope glycoprotein ectodomain. Mol. Cell 2, 605-616 (1998).

64. Popoff, M. R. Clostridial pore-forming toxins: powerful virulence factors. Anaerobe 30, 220-238 (2014).

65. Dolimbek, B. Z., Aoki, K. R., Steward, L. E., Jankovic, J. \& Atassi, M. Z. Mapping of the regions on the heavy chain of botulinum neurotoxin A (BoNT/A) recognized by antibodies of cervical dystonia patients with immunoresistance to BoNT/A. Mol. Immunol. 44, 1029-1041 (2007).

66. Weisemann, J. et al. Generation and characterization of six recombinant botulinum neurotoxins as reference material to serve in an international proficiency test. Toxins (Basel). 7, 5035-5054 (2015).

67. Battye, T. G. G., Kontogiannis, L., Johnson, O., Powell, H. R. \& Leslie, A. G. W. iMOSFLM: a new graphical interface for diffraction-image processing with MOSFLM. Acta Crystallogr. D. Biol. Crystallogr. 67, 271-281 (2011).

68. McCoy, A. J. et al. Phaser crystallographic software. J. Appl. Crystallogr. 40, 658-674 (2007).

69. Emsley, P., Lohkamp, B., Scott, W. G. \& Cowtan, K. Features and development of Coot. Acta Crystallogr. D. Biol. Crystallogr. 66, 486-501 (2010).

70. Adams, P. D. et al. PHENIX: a comprehensive Python-based system for macromolecular structure solution. Acta Crystallogr. D. Biol. Crystallogr. 66 213-221 (2010)

71. Winn, M. D. et al. Overview of the CCP4 suite and current developments. Acta Crystallogr. D. Biol. Crystallogr. 67, 235-242 (2011).

72. Brünger, A. T. Free R value: a novel statistical quantity for assessing the accuracy of crystal structures. Nature 355, 472-475 (1992).

73. Chen, V. B. et al. MolProbity: all-atom structure validation for macromolecular crystallography. Acta Crystallogr. D. Biol. Crystallogr. 66, 12-21 (2010) 
74. White, S. H., Wimley, W. C., Ladokhin, A. S. \& Hristova, K. Protein folding in membranes: determining energetics of peptide-bilayer interactions. Methods Enzymol. 295, 62-87 (1998).

75. Wimley, W. C. et al. Folding of $\beta$-sheet membrane proteins: a hydrophobic hexapeptide model. J. Mol. Biol. 277, 1091-1110 (1998).

76. Matsui, T. et al. Structural basis of the $\mathrm{pH}$-dependent assembly of a botulinum neurotoxin complex. J. Mol. Biol. 426, 3773-3782 (2014).

77. Petoukhov, M. V., Konarev, P. V., Kikhney, A. G. \& Svergun, D. I. ATSAS 2.1 -Towards automated and web-supported small-angle scattering data analysis. J. Appl. Crystallogr. 40, s223-s228 (2007).

78. Svergun, D., Barberato, C. \& Koch, M. H. CRYSOL-A program to evaluate $\mathrm{X}$-ray solution scattering of biological macromolecules from atomic coordinates. J. Appl. Crystallogr. 28, 768-773 (1995).

79. Franke, D. \& Svergun, D. I. DAMMIF, a program for rapid ab-initio shape determination in small-angle scattering. J. Appl. Crystallogr. 42, 342-346 (2009).

80. Volkov, V. V. \& Svergun, D. I. Uniqueness of ab initio shape determination in small-angle scattering. in. J. Appl. Crystallogr. 36, 860-864 (2003).

\section{Acknowledgements}

This work was partly supported by National Institute of Allergy and Infectious Diseases (NIAID) grants R01AI091823, R01AI125704, and R21AI123920 to R.J.; and by the Swiss Federal Office for Civil Protection BABS \#353005630 to A.R. and R01MH081923 to M.E.B. NE-CAT at the Advanced Photon Source (APS) is supported by a grant from the National Institute of General Medical Sciences (P41 GM103403). The Pilatus 6M detector on 24-ID-C beam line is funded by a NIH-ORIP HEI grant (S10 RR029205). Use of the APS, an Office of Science User Facility operated for the U.S. Department of Energy (DOE) Office of Science by Argonne National Laboratory, was supported by the U.S. DOE under Contract No. DE-AC0206CH11357. Use of the Stanford Synchrotron Radiation Lightsource, SLAC National Accelerator Laboratory, is supported by the U.S. Department of Energy, Office of Science, Office of Basic Energy Sciences under Contract No. DE-AC02-76SF00515. The SSRL Structural Molecular Biology Program is supported by the DOE Office of Biological and Environmental Research, and by the National Institutes of Health, National Institute of General Medical Sciences (including P41GM103393).

\section{Author contributions}

K.-h.L. and R.J. conceived the project. A.R., N.K. and J.W. generated the active full-length BoNT/A1 variants and performed the MPN assay. G.Z. and M.E.B performed the single particle counting. T.M. carried out the SAXS measurements. K.P. collected the X-ray diffraction data. K.L., R.J., M.E.B. and A.R. wrote the manuscript with inputs from all other authors.

\section{Additional information}

Supplementary Information accompanies this paper at https://doi.org/10.1038/s41467018-07789-4.

Competing interests: The authors declare no competing interests.

Reprints and permission information is available online at http://npg.nature.com/ reprintsandpermissions/

Journal peer review information: Nature Communications thanks the anonymous reviewers for their contribution to the peer review of this work.

Publisher's note: Springer Nature remains neutral with regard to jurisdictional claims in published maps and institutional affiliations.

(c) (i) Open Access This article is licensed under a Creative Commons Attribution 4.0 International License, which permits use, sharing, adaptation, distribution and reproduction in any medium or format, as long as you give appropriate credit to the original author(s) and the source, provide a link to the Creative Commons license, and indicate if changes were made. The images or other third party material in this article are included in the article's Creative Commons license, unless indicated otherwise in a credit line to the material. If material is not included in the article's Creative Commons license and your intended use is not permitted by statutory regulation or exceeds the permitted use, you will need to obtain permission directly from the copyright holder. To view a copy of this license, visit http://creativecommons.org/ licenses/by/4.0/.

(C) The Author(s) 2018 